\title{
Sustainable Wastewater Treatment Using Electrocoagulation Process Coupled With Powdered Activated Carbon
}

\section{Farooq Sher}

Coventry University

\section{Sania Zafar Iqbal}

Coventry University Faculty of Engineering and Computing

Tahir Rasheed ( $\square$ masil@sjtu.edu.cn )

shanghai jiao tong university https://orcid.org/0000-0001-9265-6303

\section{Kashif Hanif}

Coventry University Faculty of Engineering and Computing

\section{Jasmina Sulejmanović}

University of Sarajevo Faculty of Forestry: Univerziteta u Sarajevu Sumarski fakultet

\section{Fatima Zafar}

Coventry University

\section{Eder C. Lima}

Federal University of Rio Grande do Sul: Universidade Federal do Rio Grande do Sul

\section{Research Article}

Keywords: Environmental pollution, Advanced wastewater treatment, powdered activated carbon, Micropollutants, Electrocoagulation and Suspended solids.

Posted Date: February 9th, 2021

DOl: https://doi.org/10.21203/rs.3.rs-160467/v1

License: (a) (1) This work is licensed under a Creative Commons Attribution 4.0 International License. Read Full License 
1 Sustainable wastewater treatment using electrocoagulation process coupled with powdered activated carbon

Farooq Sher ${ }^{1, *}$, Sania Zafar Iqbal ${ }^{1,2}$, Tahir Rasheed ${ }^{3 *}$, Kashif Hanif ${ }^{1}$, Jasmina Sulejmanović ${ }^{4}$, Fatima Zafar ${ }^{5}$, Eder C. Lima ${ }^{6}$

${ }^{1}$ School of Mechanical, Aerospace and Automotive Engineering, Faculty of Engineering, Environmental and Computing, Coventry University, Coventry CV1 5FB, UK

${ }^{2}$ Department of Chemical and Environmental Engineering, University of Nottingham, University Park, Nottingham NG7 2RD, UK

${ }^{3}$ School of Chemistry and Chemical Engineering, Shanghai Jiao Tong University, Shanghai, 200240, China

${ }^{4}$ Department of Chemistry Faculty of Sciences, University of Sarajevo, Sarajevo, Bosnia and Herzegovina

${ }^{5}$ International Society of Engineering Science and Technology, Coventry CV1 5EH, UK

${ }^{6}$ Institute of Chemistry, Federal University of Rio Grande do Sul (UFRGS), Av. Bento Goncalves 9500, P.O. Box 15003, ZIP 91501-970, Porto Alegre, RS, Brazil

*Corresponding authors E-mail address: Farooq.Sher@coventry.ac.uk (F.Sher); masil@sjtu.edu.cn (T. Rasheed) Tel.: +44 (0) 2477657754

\section{Abstract}

In this research an electrochemical technique in combination with powdered activated carbon (PAC) for the removal of micropollutants by adsorption as an advanced stage purification step from effluents of pilot plant wastewater treatment plants (WWTP). The effluents of sedimentation tank comprised of wastewater plus PAC (WWPAC). The pilot plant mainly consists of two parts; the first one consists of electrocoagulation (EC) reactor and the second consists of electrophoretic deposition (EPD) discs and electroflotation (EF) setup. The electrocoagulation (EC) reactor is a fiber box consisting of two chambers and thirty four plates of one material (either $\mathrm{Fe}$ or $\mathrm{Al}$ ) on the whole in one EC reactor while one cell has seventeen plates. Both types of electrodes have been tested with the outflow of sedimentation tank. The outflow from the sedimentation tank has been 
32 entered into the EC reactor for the determination of EC reactor efficacy for the successful

33 accomplishment of EC process at the designed pilot plant for WW treatment. The effect of

34 different operational parameters; PAC dosage $(20 \mathrm{mg})$, electrode nature ( $\mathrm{Fe}$ and $\mathrm{Al})$, current

35 density $\left(0.34-2.02 \mathrm{~A} / \mathrm{m}^{2}\right)$ has been studied to find out the optimum conditions. Sludge volume

36 index (SVI) of the sludge, thermogravimetric (TG), differential thermal analyses (DTA) and

37 particle size distribution (PSD) of the flocs generated after the EC process has also been studied.

38 The turbidity, $\mathrm{pH}$ and conductivity of effluents before and after EC treatment has also been carried

39 out. This pilot plant research gave promising results for future work in advance wastewater

40 treatment direction.

41 Keywords: Environmental pollution; Advanced wastewater treatment; powdered activated

42 carbon; Micropollutants; Electrocoagulation and Suspended solids.

\section{$43 \quad 1$ Introduction}

44 The presence of organic pollutants in aquatic environment with the potential to cast adverse

45 biological impacts, have been recognized for many years. In recent years, the authorities dealing

46 with water has become more worried about the presence of harmful substances in water resources

47 used for various purposes. The technical difficulties for inhibiting the discharge of micro-

48 pollutants into the aquatic environment rise from inadequate removal in wastewater treatment

49 plants (WWTPs) and the subsurface leakage of sewers. However, the other sources like

50 agriculture, pharmaceutical, food additives, construction materials, cosmetics ingredients and

51 naturally occurring substances such as hormones are also the major sources of pollutants in water

52 bodies. The municipal WWTPs are usually designed to remove degradable organic compounds,

53 solids and some nutrients. 
54 Many treatments like filtration, adsorption, aerobic degradation, froth floatation, flocculation and

55 electrocoagulation (EC) have been known till now for the removal of micropollutants and

56 anthropogenic pollutants (Eryuruk, Un, \& Ogutveren, 2018). While the EC is the most studied

57 technique for the said purpose in WW treatment process (Sher, Hanif, Iqbal, \& Imran, 2020). It is

58 a multistep process being run by electric current for the agglomeration of micropollutants by using

59 electrodes (coagulant) through redox reaction (Izadi, Hosseini, Darzi, Bidhendi, \& Shariati, 2018).

60 Some inorganic chemical like $\left(\mathrm{NH}_{4}\right)_{2} \mathrm{SO}_{4}$ and $\mathrm{FeCl}_{3}$ were used as coagulants to carry out the

61 conventional electrocoagulation processes. Powder activated carbon (PAC) is a finely grounded

62 activated carbon which has promising effects due to its unique properties such as high surface area.

63 It is mixed with the wastewater so that the effluent ingredients can be adsorbed on the surface of

64 the fine activated carbon particles. Since both the natural organic matter and the micropollutants

65 adsorb onto the activated carbon, the PAC process is best located after extensive biological

66 treatment. When loaded with organic matter and micropollutants, the PAC has to be separated

67 from cleaned wastewater and should be disposed of (Bazrafshan, Alipour, \& Mahvi, 2016). There

68 are numerous separation processes used for this purpose e.g. lamella separator, micro sieve,

69 Sedimentation followed by cloth filtration, sand filtration and ultrafiltration (membrane) etc.

70 Usually, the sedimentation of the PAC treated wastewater is possible only by the addition of

71 coagulants and flocculating agents such as metal salts $\left(\mathrm{FeCl}_{3}, \mathrm{AlCl}_{3}\right.$ etc.) and organic polymers

72 (Bazrafshan et al., 2016). Solid particles suspended or dissolved in water or wastewater tends to

73 be charged negatively, so colloidal particles tend to repel each other, thus preventing the process

74 of aggregation and settlement of these particles. It is very difficult to remove these particles from

75 wastewater because of their small size to pass through the filter paper and they do not settle down

76 under the action of gravity. For the effective removal of micropollutants, the colloids need to be 
aggregated to increase in size to stay on the filtration media. Precipitation of a soluble product

78 occurs when antisolvent is added to reduce the solubility of desired compound. So that precipitates

79 can be easily separated by different physical treatments. The use of coagulants is done to bring

80 about particle's agglomeration (coagulation). Coagulants are selected depending upon the electric

81 charge on particles and the nature of the particles such as their affinity to adsorb water.

82 The EC process has been used for the removal of wastewater pollutants as it is an electrochemical

83 process, proceeds by the passage of electric current from the metal electrodes (coagulants)

84 (Hashim et al., 2019). This process consists of the transformation of water retaining hazardous

85 pollutants to the non-hazardous materials by redox reactions. Due to the simple assembly, selective

86 capability, short reaction period, easiness of handling, safety of the process, less use of chemicals

87 and good purification efficiency, EC has been recognized as a famous green technology (Hashim

88 et al., 2019; Papadopoulos et al., 2019). To carry out the redox reaction, necessary force

89 (electromotive) is supplied by the electric current (I) which convert the soluble contaminants to

90 the stable state that are comparatively less soluble, less colloidal and less emulsifiable than the

91 previous contaminants at equilibrium values. By this process the soluble contaminants are

92 converted into hydrophobic compound or precipitates which are easily separated out by the use of

93 various separation techniques. By the use of EC method, no secondary contaminants form because

94 of the use of very less amount of chemicals so there is no need of neutralization reaction which is

95 the common advantage of this process (Ensano et al., 2019).

96 The EC technology comprised of three purification stages such as; (1) generation of coagulants by

97 the electrolytic oxidation of sample wastewater; (2) destabilization of contaminants, deterioration

98 emulsification and particle suspension; (3) for the generation of floc, the agglomeration of resultant

99 particles consisting of colloids entangled in sludge layer formed after coagulation reaction 
100 (Elazzouzi, El Kasmi, Haboubi, \& Elyoubi, 2018). These flocs having similarity with chemical

101 flocs, therefore they can be easily separated out by the sand filtration process due to their larger

102 size, stability, containing less amount of water and acid resistance (Omwene, Kobya, \& Can, 2018;

103 Tanyol, Ogedey, \& Oguz, 2018). A number of electrochemical reactions are involved in this

104 process which occur at anode and cathode in the sequence as mentioned in equations (1-7). The

105 electro-floatation process occurs during EC process which involves evolution of $\mathrm{H}_{2}$ gas at cathode

106 in the form of bubbles which discards particles by flotation (Devlin et al., 2019).

107 These chemical reactions are carried out to generate metallic electrodes' (anode: Fe or Al)

108 hydroxides and coagulants for the destruction, coagulation and adsorption of pollutants for

109 wastewater (Tanyol et al., 2018). From the reaction 1 and 4 it is obvious that the metal cations

$110\left(\mathrm{Fe}^{2+}\right.$ and $\left.\mathrm{Al}^{3+}\right)$ get dissolved from the relevant anode to the aqueous phase of the reactor. These

111 metal ions can further form various monomeric and polymeric hydroxides during electrochemical

112 process to each electrode. The conversion of metallic cations into $\mathrm{Al}(\mathrm{OH})_{3}$ and $\mathrm{Fe}(\mathrm{OH})_{2}$

113 hydroxides in (reaction 3 and 6) are $\mathrm{pH}$ dependent reactions. Therefore, the final species formed

114 act as adsorbents for micro-pollutants.

115 The reactions during EC process at aluminum electrode are as:

116 Anode:

$$
\mathrm{Al}(\mathrm{s}) \rightarrow \mathrm{Al}^{3+}(\mathrm{aq})+3 \mathrm{e}^{-}
$$

118 Cathode:

$$
3 \mathrm{H}_{2} \mathrm{O}+3 \mathrm{e} \rightarrow 3 / 2 \mathrm{H}_{2}(\mathrm{~g})+3 \mathrm{OH}^{-}
$$

120 Overall:

$$
\mathrm{Al}^{3+}(\mathrm{aq})+3 \mathrm{H}_{2} \mathrm{O} \rightarrow \mathrm{Al}(\mathrm{OH})_{3}+3 \mathrm{H}^{+}(\mathrm{aq})
$$

122 Reactions at iron electrode during EC are: 
123 Anode:

125 Cathode:

$$
2 \mathrm{H}_{2} \mathrm{O}+2 \mathrm{e}^{-} \rightarrow \mathrm{H}_{2}+2 \mathrm{OH}^{-}
$$

127 Overall:

$$
\mathrm{Fe}^{2+}(\mathrm{aq})+2 \mathrm{H}_{2} \mathrm{O} \rightarrow \mathrm{Fe}(\mathrm{OH})_{2}+\mathrm{H}_{2}
$$

130 In literature, purification of colour, ammonia, chemical oxygen demand (COD) and phosphorus

131 by using various electrodes such as Mg (Devlin et al., 2019), Fe (Chou, Wang, \& Chang, 2009),

132 Al (Hashim et al., 2019) and steel (Mahmad, Rozainy, Abustan, \& Baharun, 2016) have been 133 evaluated at different $\mathrm{pH}$ and high current values, also PAC has been used for this purpose along 134 with all these electrodes (Bonvin, Jost, Randin, Bonvin, \& Kohn, 2016; Mailler et al., 2015). This 135 study is performed at pilot plant scale with electrocoagulation process in combination with PAC 136 using different current densities and coagulants. The objectives are focused to study the role of 137 current densities, amount of PAC and coagulant's nature in the production of flocs and EC process 138 at this pilot plant and the evaluation of optimised conditions for this process. All experiments were 139 conducted individually using Fe and Al coagulants/electrodes and then amount of suspended solids 140 (SS) is also calculated. Furthermore, the technique of membrane filtration has also been used for 141 the determination of SS amount in the wastewater.

\section{Experimental setup}

\section{$143 \quad 2.1$ Wastewater sampling}

144 Wastewater sample from the wastewater treatment plant was taken for the experiments. The

145 wastewater characteristics from secondary sedimentation tank are elaborated in Table 1. After 
146 maintaining constant operating conditions of EC setup, the inflow and outflow points were fixed

147 for obtaining homogenous samples every time. To make sure the constant homogeneous sample's

148 composition, samples were taken at short intervals of time instead taking all sample at once.

\section{$149 \quad 2.2$ Powdered activated carbon (PAC) dosing}

150 In two ways, activated carbon can be used; powder form of granular form. PAC usually has a size

151 less than $0.074 \mathrm{~mm}$ diameter (200 mesh). The bulk density of PAC is ranging from $360-740 \mathrm{~kg} / \mathrm{m}^{3}$.

152 The total surface area of PAC is $800-1800 \mathrm{~m}^{2} / \mathrm{g}$. The typical characteristics of PAC are given in

153 Table 2 . The $20 \mathrm{mg} / \mathrm{L}$ dosage of PAC was used for each run of electrocoagulation process with Fe

154 and Al. PAC slurry is prepared in a $200 \mathrm{~L}$ closed tank. The amount which has to be added in the

155 mixing tank in order to achieve $20 \mathrm{mg} / \mathrm{L}$ concentration in the outflow of mixing tank was

156 calculated to be about $2 \mathrm{~g} / \mathrm{L}$ in the PAC slurry. The wastewater stream coming to the mixing tank

157 was adjusted accordingly at about $1000 \mathrm{~L} / \mathrm{h}$ while the PAC slurry rate is adjusted at about $10 \mathrm{~L} / \mathrm{h}$

158 with the help of a small pump for an open mixing tank of volume $150 \mathrm{~L}$. The PAC added to the

159 PAC slurry tank was used from a storage tanker placed outside the lab at ambient temperature.

\section{$160 \quad 2.3$ Pilot plant setup}

161 The experimental setup of EC plant is represented in Fig. 1. A feed/ mixing open tank is used for

162 this experiment. Some contaminants settle down during the experiment like suspended solids (SS),

163 so for the maintenance of consistent inflow rate and continuous stirring, a stirrer is fitted in the

164 feeding tank (150 L). PAC slurry is made in a $200 \mathrm{~L}$ closed tank, also equipped with a mechanical

165 stirrer for a homogeneous outflow concentration of the PAC slurry to the feed tank. PAC Slurry

166 tank is connected to the feed tank/mixing tank through a small pump (range 8-12 L/h) operating

167 at about $10 \mathrm{~L} / \mathrm{h}$ and pumping in PAC at about $2 \mathrm{~g} / \mathrm{L}$ in the feed tank. A pump (250-1500 L/h) is

168 used to fed effluent to the EC reactor from the feed tank and for maintaining $500 \mathrm{~L} / \mathrm{h}$ inflow to EC 
reactor, a flow meter is attached in line. The pilot plant setup comprises of two main sections: first

170 part has an EC reactor while the second part has EF setup and EPD discs as shown in Fig. 1.

172 The EC reactor is made up of fibre box, consists of two chamber attached in series having slits

173 inside for the insertion of metal plates performing the function of anodes and cathodes. There are

174 total thirty four plates of one material (Fe or $\mathrm{Al})$ in the whole reactor from which 17 plates are

175 present in each cell. For the better operation of system, the height of plates is increased to about 3

$176 \mathrm{~cm}$ and $3 \mathrm{~mm}$ in length and diameter respectively by attaching slits inside the EC cells by using

177 plastic cylindrical objects in EC reactor. Furthermore, the plates are connected to DC power

178 supply via polarity changer circuit. In this connection, plates play the role of bipolar electrodes in

179 parallel circuit. Moreover, the polarity changer circuit has the control to change the polarity of

180 electrodes at various time intervals and hence equally consuming all the electrodes. The electrode's

181 side facing anode is negatively charged and vice versa on the opposite side of metal electrode. To

182 enter the inflow into the reactor, the EC reactor is provided with a circular inlet hole where

183 connecting pipes are attached.

184 A rectangular opening at reactor's outlet, a circular hole at the bottom of reactor is fitted for the 185 overflow of water and an auxiliary glass lid is used for EC reactor covering to ascertain a better 186 inside view of the process and for the control of parameters by visually observing the procedure.

187 The electrode plates inside the reactor constitute an effective surface area of about $1.49 \mathrm{~m}^{2}$ with 188 the dimensions of $300 \times 155 \times 3 \mathrm{~mm}$. Different values of current densities were selected for $\mathrm{Al}$ and 189 Fe electrodes in this experiment such as $0.67-1.34 \mathrm{~A} / \mathrm{m}^{2}$ and $0.34-0.67 \mathrm{~A} / \mathrm{m}^{2}$ ranges current 190 densities were used for Fe and Al electrodes respectively. The results showed that the Al electrode 191 provided more agglomeration of suspended solids at the lower densities of current as compare to 
192 Fe electrode which required higher densities of current for noticeable results. The Al electrode was

193 selected for this treatment as observed previously, due to the requirement of lower densities of

194 current and economic factor. The electrocoagulation inflow rate was kept at $500 \mathrm{~L} / \mathrm{h}$. The solutions

195 of $\mathrm{NaOH}$ and $\mathrm{H}_{2} \mathrm{SO}_{4}$ were used for the maintenance of inflow $\mathrm{pH}$ on requirement. The settings of

196 the EC reactor for Fe and Al derived coagulation of WWPAC is inserted in Table 3.

\section{$197 \quad 2.4$ Membrane filtration technique}

198 The membrane separation process was used for the calculation of suspended solids in the sample 199 by following the protocol of DIN 19643-2 (Dudziak, Wyczarska-Kokot, Łaskawiec, \& Stolarczyk, 200 2019). After treatment, they called as after filtration solids (AFS). The filtration was carried by

201 using the filter papers which allowed only those particles to pass on having the diameter of $<0.45$

$202 \mu \mathrm{m}$ at the 5 bars specific nitrogen pressure followed by drying the wet filter papers in oven at 105

$203{ }^{\circ} \mathrm{C}$ for about 1 hour which evaporated all moisture content and left only solid residues on the paper.

204 These solid particles were kept in desiccator for cooling down for 30 minutes. Finally, the weight 205 of filter papers was measured for the calculation of total suspended solids in the treated wastewater.

206 Furthermore, each sample was taken to AFS setup three times for taking the average experimental 207 calculated values. On the basis of coagulant dissolution property and floc formation ability, the 208 quantitative analysis was performed by the comparison of AFS of inflow and outflows of samples.

209 For the observation of the reliability of the treatment, the amount of coagulants was measured 210 experimentally and theoretically which was added during the experiment for flocs generation and

211 this was done after AFS calculation. The experimental calculation of optimum dosing amount of

$212 \mathrm{Al}$ and Fe coagulants in outflows is the major goal of this study. Spectrophotometric analysis was

213 done for the calculation of total Fe amount in outflow and gravimetric analysis was performed for 
214 the measurement of $\mathrm{Al}$ amount in outflow (Baierle et al., 2015). While theoretical measurement

215 of Fe and Al coagulants' doses is done by using Eq. (7) (Heidmann \& Calmano, 2010).

216

217

$$
C_{x}=\frac{m_{\text {total }, x}}{V_{\text {total,liquid }}}=\frac{\mathrm{I} \times \mathrm{t} \times m_{x} \times \mathrm{N}}{\mathrm{Q} \times \mathrm{t}}=\frac{\mathrm{I} \times m_{x} \times \mathrm{N}}{\mathrm{Q}}
$$

218 where $\mathrm{C}_{x}(\mathrm{mg} / \mathrm{L})$ represents the released metal amount (Fe or $\mathrm{Al}$ ) after the treatment form the

219 electrolysis cell; mtotal,x $(\mathrm{mg})$ is the mass of metal released after process by Faraday's law in

220 retention time; $\mathrm{V}_{\text {total,liquid }}(\mathrm{L})$ shows the total effluent's volume within the range of retention time;

221 I (A) is the current applied; $\mathrm{N}$ shows the channels' number; $\mathrm{Q}(\mathrm{L} / \mathrm{s})$ is the rate of flow and $\mathrm{m}_{\mathrm{x}}$

222 represents the electrochemical equivalent for metals. For $\mathrm{Al}$ and Fe metals, electrochemical 223 equivalent values are $(0.093 \mathrm{mg} / \mathrm{C})$ and $(0.193 \mathrm{mg} / \mathrm{C})$ respectively.

224 To characterise the sludge development, sludge volume index (SVI) that is the volume (mL)

225 occupied by 1 gram of sludge after settling in $1 \mathrm{~L}$ amount of treated liquor for 30 min was

226 measured. The SVI can be calculated by using Eq. (8) (Papadopoulos et al., 2019).

$$
\text { SVI }=(\text { Settled volume of sludge } \times 1000) / \text { MLSS }
$$

228 where MLSS is the mixed liquid suspended solids and used for the calculation of SVI.

\section{$229 \quad 2.5$ Flocs characterisation}

230 The change in physical or chemical properties of materials/ flocs after EC process was carried out

231 by thermal gravimetric analyser (TGA) which consists of a sample pan attached with a precision

232 balance. The pan is kept inside the furnace at constant heating during the experiment. Moreover,

233 the mass of sample is examined during the course of experiment. A sample of pure gas controls

234 the sample environment. However, the nature of gas can be inert or reactive that can flow over the

235 sample or eliminates through an exhaust. The equipment used for thermal gravimetric analysis 
was Netsch STA 409 C developed by Netsch Gerätbau GmbH. It combines differential thermal

237 analysis (DTA) and TGA, so allowing simultaneous measurement of thermal properties and mass

238 change (Peng et al., 2016).

239 A list of values of mathematical function defining the relative amount by mass according to the

240 size of particles dispersed in liquid in the form of powder or granular material is known as the

241 particle size distribution (PSD). PSD characterization is done of the effluent after EC treatment

242 with metal electrodes ( $\mathrm{Fe}$ and $\mathrm{Al})$. Further to observe the flocs formed after the EC process in

243 detail, 1 litre of sample is separated during the experiments every time. The samples were

244 separately taken to the electrodes ( $\mathrm{Fe}$ and $\mathrm{Al}$ ) with their respective current densities. The laser

245 granulometer, the Mastersizer 3000 from Malvern is used to perform PSD (Lee \& Gagnon, 2016).

246 This device can be used to measure the particles' size of 0.01 to 3500 microns range. Two sources

247 of light were used for measurement; red and blue lights of the wavelengths of $632.8 \mathrm{~nm}$ and 470

248 nm respectively.

\subsection{Measurement of $\mathrm{pH}$ and turbidity}

250 Turbidity was measured using an electronic turbidity meter. A pH meter an electronic device was

251 used for the measurement of $\mathrm{pH}$ of the samples before and after EC process. A pH meter usually

252 consists of two parts: a measuring glass probe and an electronic meter for the measurement of $\mathrm{pH}$

253 which is displayed in digits.

\section{Results and discussion}

255 It is an established fact that concentration of 10-20 mg PAC per litre of wastewater and average

256 retention time of 15-30 minutes can remove efficiently the micropollutants from the wastewater

257 (Kårelid, Larsson, \& Björlenius, 2017). The sedimentation of colloidal micropollutants with the 
PAC is possible by the addition of coagulants and flocculants $\left(\mathrm{FeCl}_{3}, \mathrm{AlCl}_{3}\right.$ etc.) and organic

259 polymers. Because of the small particle size in combination with the high flow rates, the separation

260 of PAC loaded with micropollutants and suspended solids is a difficult task. Besides the cost of

261 these chemical coagulants, they have a negative effect such as they lower the adsorption capacity

262 of PAC by blocking surface pores. Electrocoagulation process can remove the side reaction of

263 lowering adsorption capacity of PAC and also have several other operational advantages in

264 wastewater treatment. In EC electrochemical process, the amount of current density plays a vital

265 role. Further, different values of current densities were used at Fe and Al electrodes to test the role

266 of current density on coagulation process of solid particles at the flow rate of $500 \mathrm{~L} / \mathrm{h}$.

\section{$267 \quad 3.1 \quad$ EC process with Fe coagulation}

268 After entering the wastewater from sedimentation tank to the EC reactor having Fe electrodes,

269 PAC was mixed in the amount of $20 \mathrm{mg} / \mathrm{L}$ to the inflow water at the current range of 1-2 A and

270 current density of $0.67-1.34 \mathrm{~A} / \mathrm{m}^{2}$. The Fig. 2 shows that the AFS production is dependent on the

271 amount of applied current and it can also be concluded from the AFS amount established in inflow

272 and outflow of EC reactor. The indication of dissolution of metal electrode is obtained by higher

273 amounts of outflows than in the inflows during the EC process. Furthermore, it is can be assumed

274 that Fe electrode dissolution is the main reaction which occurs at anodes during specific amount

275 of current densities when pH become neutral (Sasson, Calmano, \& Adin, 2009).

276 In the Fig. 3, theoretically calculated amounts of Fe coagulant, Fe and AFS obtained from outflows

277 were compared with the current densities values taking it as a variable. Reaction (6) shows the

278 amount of Fe obtained at outflow of EC reactor in which by the reaction of 1 mole of Fe (s) and 2

279 moles of water produces 1 mole of $\mathrm{Fe}(\mathrm{OH})_{2}$. It was supposed that complete amount of metal in $\mathrm{Fe}$

280 electrode was consumed for the production of $\mathrm{Fe}(\mathrm{OH})_{2}$ precipitates with dirty green appearance. 
281 After adding PAC amounts, new flock were formed causing the color change from dirty green

282 precipitates of $\mathrm{Fe}(\mathrm{OH})_{2}$ to dark black.

283

284 A new set of experiments were designed to know and verify the fact about the produced $\mathrm{Fe}$ (II) and 285 consequently $\mathrm{Fe}(\mathrm{OH})_{2}$. When the outflow containing $\mathrm{Fe}(\mathrm{OH})_{2}$ was treated with enough amount of $28625 \% 1 \mathrm{M} \mathrm{HCl}$, the new product formed $\mathrm{Fe}(\mathrm{Cl})_{2}$ was fully soluble in water and made a clear solution, 287 which is then subjected to AFS again. The reaction took place while treating the outflows produced 288 by Fe electrodes with $\mathrm{HCl}$ is shown in reaction (9).

$$
\mathrm{Fe}(\mathrm{OH})_{2}+\mathrm{HCl} \rightarrow \mathrm{FeCl}_{2}+2 \mathrm{H}_{2} \mathrm{O}
$$

292 As shown in Fig 4, the red shaded area in the bars represents the amount of AFS after treating with

$293 \mathrm{HCl}$ and the normal height of the bars (green shaded) represents the amount of AFS produced 294 without treating with $\mathrm{HCl}$. Furthermore, it can be clearly seen that the amounts of AFS produced 295 after treating with $\mathrm{HCl}$ are approximately the same amount as it is in the inflow stream before the

296 EC process as shown in Fig. 2. This fact proved the calculations for the Fe amount in the outflow 297 streams based on the fact that the whole amount of produced precipitates are of $\mathrm{Fe}(\mathrm{OH})_{2}$. That on 298 the treatment with $\mathrm{HCl}$ becomes soluble in solution while AFS of $\mathrm{HCl}$ treated outflow gave the 299 amount which have to be introduced into the inflow to EC process for this specific set of 300 experiments.

\section{$301 \quad 3.2 \quad$ EC process with Al coagulation}

302 When wastewater was entered into EC reactor (with Al electrodes) from the sedimentation tank, 303 PAC was mixed in amount of $20 \mathrm{mg} / \mathrm{L}$ into the inflow with the current and current density in the 
304 range of $0.5-1 \mathrm{~A}$ and $0.34-0.67 \mathrm{~A} / \mathrm{m}^{2}$ respectively. The AFS amount was measured before and

305 after the EC process present in the inflow and outflow and represented in Fig. 5 which also shows

306 that the AFS amount production is directly proportional to the applied current. The dissolution of

307 metal electrodes is the basic reaction occurring at anodes, here the same case is with Fe electrodes.

309 The amount of Al coagulant dose, theoretically calculated amount of Al and AFS produced with

310 the corresponding current density range are shown in Fig. 6. The measurement of amount of Al

311 is shown by the reactions (1-3) in which 1 mole of $\mathrm{Al}$ and 3 moles of water reacts to form $\mathrm{Al}(\mathrm{OH})_{3}$

312 which polymerized to form hydroxide compounds (Izadi et al., 2018). The assumption is made

313 that whole $\mathrm{Al}$ electrode consume up to produce $\mathrm{Al}(\mathrm{OH})_{3}$ and this assumption is proved

314 experimentally by the reaction with $\mathrm{HCl}$.

316 In this experiment as well, the outflows obtained after treating with EC based on $0.5 \mathrm{~A}, 0.75 \mathrm{~A}$

317 and $1 \mathrm{~A}$ current settings, were treated with $\mathrm{HCl}$ to verity the fact that the whole amount which was

318 produced by $\mathrm{Al}$ electrodes during $\mathrm{EC}$ process was $\mathrm{Al}(\mathrm{OH})_{3}$. When the outflows containing

$319 \mathrm{Al}(\mathrm{OH})_{3}$ was treated with enough amount of $25 \% 1 \mathrm{M} \mathrm{HCl}$, the new product formed $\mathrm{Al}(\mathrm{Cl})_{3}$ which

320 was fully soluble in water and made a clear solution, which is then subjected to AFS again. The

321 reaction took place while treating the outflows produced by $\mathrm{Al}$ electrodes with $\mathrm{HCl}$ is shown in 322 reaction (10).

$$
\mathrm{Al}(\mathrm{OH})_{3}+3 \mathrm{HCl} \rightarrow \mathrm{AlCl}_{3}+3 \mathrm{H}_{2} \mathrm{O}
$$

325 As shown in the Fig. 7, the red shaded area in the bars represents the amount of AFS after treating 326 with $\mathrm{HCl}$ and the normal height of the bars (blue shaded) represents the amount of AFS produced 
327 without treating with $\mathrm{HCl}$. Moreover, it can be clearly noticed that the produced amount of AFS

328 after treating with $\mathrm{HCl}$ are approximately the same amount as was introduced in the inflow stream

329 before the EC process as shown in Fig. 5. This fact proved the calculations for the $\mathrm{Al}$ amounts in

330 the outflow streams based on the fact that the whole amount of produced precipitates are of

$331 \mathrm{Al}(\mathrm{OH})_{3}$, which on treatment with $\mathrm{HCl}$ become soluble in solution and the AFS of the $\mathrm{HCl}$ treated

332 outflow gives us the amount which have to be introduced in the inflow to EC Process for this

333 specific set of experiments.

\section{$334 \quad 3.3$ Settling characteristics of sludge}

335 The Fig. 8 (a) and (b) show the settled volume of sludge after two hours of settling, for Fe and $\mathrm{Al}$

336 electrodes at different applied current settings for the EC operation with wastewater and PAC. The

337 sludge volume index of the sludge produced by Fe and Al electrodes according to Eq. (9) while

338 operating with wastewater and PAC is measured at various current amounts. The Sludge volume

339 index (SVI) of sludge produced by $\mathrm{Al}$ and Fe electrodes operation with wastewater is incorporated

340 in Table 4. The SVI was used by R. Katal et al., (Katal \& Pahlavanzadeh, 2011) for the settling

341 characteristics of EC sludge produced by $\mathrm{Al}$ and Fe electrodes.

343 According to Zodi et al., textile wastewater treatment by EC process. The SVI values generated

344 by $\mathrm{Fe}$ and $\mathrm{Al} \mathrm{EC}$ process found to be varies with current density are in the range of $0-215 \mathrm{~mL} / \mathrm{g}$

345 at 50-200 A/ $\mathrm{m}^{2}$ (Zodi, Potier, Lapicque, \& Leclerc, 2009). This research is designed at pilot plant

346 scale, and the EC process was run in combination with PAC dosage, the obtained results of SVI

347 with Fe and Al EC process with WWPAC effluents were very interesting. To some extent similar

348 results of SVI were obtained but at lower values of current densities. The SVI found by the

349 designed pilot plant operations is $23-208 \mathrm{~mL} / \mathrm{g}$ and $58-312 \mathrm{~mL} / \mathrm{g}$ for $\mathrm{Al}$ and $\mathrm{Fe}$ electrodes 
respectively. However, the sludge produced by iron was denser and in the form of a compact layer,

351 while the sludge produced by Al electrodes was observed to be fluffy and light weight.

\section{$352 \quad 3.4$ Outflow effluent analysis for $\mathbf{p H}$ and turbidity}

353 Other factor such as $\mathrm{pH}$ also plays a vital part in the reactions of EC reactor in addition to the effect

354 of current applied. The effect of $\mathrm{pH}$ is also confirmed by the literature which states that $\mathrm{pH}$ of

355 wastewater changes after passing through the EC reactor due to the cathode reactions $\left(\mathrm{H}_{2}\right.$

356 evolution). It also depends on the selection of anode and initial pH of inflow water (Eryuruk et al.,

357 2018; Izadi et al., 2018; Yavuz \& Ögütveren, 2018). The increase in AFS amount in the outflow

358 was observed by the increase of current density in the previous section. The effect of $\mathrm{pH}$ was

359 observed on the inflow and outflow of the EC reactor and on the production of AFS at the applied

360 conditions of current density for both type of electrodes. The outflow's $\mathrm{pH}$ was increased

361 correspondently with the increase in current density in all the experiments (Izadi et al., 2018). The

362 outflow had a slight increase in $\mathrm{pH}$ with both electrodes ( $\mathrm{Fe}$ and $\mathrm{Al}$ ) in both series of all the 363 experiments.

365 The $\mathrm{pH}$ of the reaction solution changes during the course of EC process and this is a well-known

366 side reaction of the process. The $\mathrm{pH}$ increase was observed during the whole set of experiments

367 performed in two series with Fe and $\mathrm{Al}$ electrodes. However, the mechanism of EC is highly

368 dependent on the conductivity of the aqueous medium. In the whole set of experiments done with

369 metal electrodes ( $\mathrm{Al}$ and $\mathrm{Fe}$ ), the conductivity remained almost similar before and after the EC

370 process. Therefore, it can be mentioned that the conductivity remained constant over the EC

371 process. It can be observed that the turbidity of the effluents is increased after EC process. The

372 turbidity of the sample increases after the EC process because of the hydroxide formation. No 
373 matter which metal has been used, the turbidity varies directly as the current density increases.

374 However, in this study the turbidity generated with $\mathrm{Al}$ electrodes is higher than Fe electrodes and

375 a sharp rise is observed in turbidity values at same current Fig. 9 (Sasson et al., 2009).

\section{$376 \quad 3.5 \quad$ Flocs production investigation}

\section{$377 \quad$ 3.5.1 Thermogravimetric analysis}

378 Thermogravimetric analysis (TGA) was made to understand the thermal behaviour of the flocs

379 produced from EC process. Thermogravimetric (TG) and differential thermal analysis (DTA) plots

380 for iron and aluminum flocs are shown in Fig. 10. The DTA signal which is represented the amount

381 of released energy and that also corresponds to the maximum amount at approximately about 550

$382{ }^{\circ} \mathrm{C}$ and hence confirming the exothermic reaction nature of the tested substances. TGA and DTA

383 analysis for iron and aluminium flocs were done. Observing these plots, there are clearly four

384 zones visible that represent the mass loss of the flocs while exhibiting the analysis. In the first

385 zone, which corresponds to the $25-150{ }^{\circ} \mathrm{C}$, the usual mass loss happened for both the Fig. 10 (a)

386 and (b) flocs (Sahu, Mazumdar, \& Chaudhari, 2019).

388 The first zone here corresponds to the mass loss on the basis of moisture removal or drying of the

389 matter. In the second zone, where the temperature corresponds to $150-350{ }^{\circ} \mathrm{C}$ and the mass loss

390 can be assigned as oxidation, decomposition or transformation of the easily degradable substances.

391 In the third zone, the behaviour of the $\mathrm{Fe}$ and $\mathrm{Al}$ flocs is quite different, depending upon the 392 corresponding products formed during the EC process. The mass loss in case of Fe flocs 393 corresponding to temperature range of $300-430{ }^{\circ} \mathrm{C}$ is mainly related to the decomposition of $394 \mathrm{Fe}(\mathrm{OH})_{3}$, which is a highly exothermic reaction according to DTA signals generated. On the other 395 hand, the mass loss in case of $\mathrm{Al}$ flocs corresponding to temperature range of $300-470^{\circ} \mathrm{C}$ is mainly 
396 related to the decomposition of $\mathrm{Al}(\mathrm{OH})_{3}$ and the energy release was even higher as compared to

397 the Fe flocs. The more mass loss in case of the Al flocs indicates that there are more easily

398 degradable salts of $\mathrm{Al}$ present in the $\mathrm{Al}$ flocs. In the zone of rest matter or residual non-degradable

399 substances, the Fe flocs tend to have more solid metal residues than $\mathrm{Al}$ flocs.

401 The amount of rest matter for Fe flocs is more than that of Al flocs, showing that the amount of 402 coagulation dose was also higher in case of Fe flocs, as the sample was taken at about $2 \mathrm{~A}$ and the 403 lesser amount of residues in the Al flocs is also justified on the basis that the lesser current was 404 applied to take the sample, corresponding to 1A. As a conclusion for the TG and DTA graphs, at 405 optimum conditions defined for the PAC series, which are $2 \mathrm{~A}$ for the Fe flocs and $1 \mathrm{~A}$ for the $\mathrm{Al}$ 406 flocs, both types of flocs exhibits the same sort of behaviour in the initial phases, but in the main 407 degradation phase of the coagulant salts formed during the course of the process, $\mathrm{Al}$ flocs exhibit 408 more mass loss in comparison to the Fe flocs and Fe flocs are found to be giving more residual 409 matter in the end in contrast to Al flocs.

\section{$410 \quad$ 3.5.2 Particle size distribution}

411 For PSD analysis by using laser granulometer, the samples were taken from outflow streams after 412 EC reactor process having PAC, Fe and $\mathrm{Al}$ electrodes. The results are shown in Fig. 11, when Fe 413 and $\mathrm{Al}$ were used for the purpose of coagulation at the current values of 0.5-2 A. In PSD analysis, 414 the cumulative volume $(\%)$ is shown against the diameter $(\mu \mathrm{m})$ of particles. Fig. 11 confirms that 415 the bigger flocs were produced with the higher amount of current application which could be easily 416 separated by secondary sedimentation processes. The reason for the bigger size of flocs with 417 operation of wastewater and PAC by Al electrodes can be the result of the special structure of $\mathrm{Al}$ 418 complexes formed during the EC process. 


\section{Conclusions}

420 The design of electrocoagulation (EC) technique is revived to fulfil the needs of this method for

421 the removal of micropollutants from wastewater. Moreover, an advanced research of PAC is used

422 in combination with EC. By changing the amount of current applied, the selected process is tested

423 for obtaining the improved quality water from the outflow of EC pilot scale reactor. The results

424 are compared for a good downstream separation method. On the basis of the Faraday's Law and

425 the amount of AFS produced, the optimum doses of Fe and Al coagulants are calculated. The

426 dosing amount of coagulants increased by increasing the current density with $\mathrm{Fe}$ and $\mathrm{Al}$ metal

427 electrodes. The best results obtained for $\mathrm{Al}$ and $\mathrm{Fe}$ metal electrodes for variable range of current

428 and current densities are $1 \mathrm{~A}\left(0.67 \mathrm{~A} / \mathrm{m}^{2}\right)$ and $2 \mathrm{~A}\left(1.34 \mathrm{~A} / \mathrm{m}^{2}\right)$ respectively for the highest amount

429 of AFS production. Various other analyses of $\mathrm{pH}$, turbidity, conductivity, TGA, DTA, SVI, PSD

430 have been performed to deeply study the whole process, before and after the reaction. From all

431 analyses mentioned before, better results with lower values of current density were obtained by $\mathrm{Al}$

432 electrodes. Furthermore, all these experiments are performed on the designed EC pilot plant and

433 gained remarkable results which are a promising opportunity for other researchers to use similar

434 electrodes system and natural coagulant material at this test plant in future. Additionally, this pilot

435 plant research could have future work in advance wastewater treatment such as using other

436 electrodes system and natural coagulant materials.

\section{Declarations}

\section{Ethical Approval}

439 Not applicable

440 Consent to Participate

441 Not applicable 
443 Not applicable

444 Authors Contributions

445 Farooq Sher; Tahir Rasheed: Conceptualization, Methodology, Software Farooq Sher;

446 Sania Zafar lqbal.: Data curation, Writing- Original draft preparation. Tahir Rasheed:

447 Visualization, Investigation. Farooq Sher: Supervision.: Kashif Hanif; Fatima Zafar:

448 Software, Validation.: Farooq Sher; Tahir Rasheed; Jasmina Sulejmanović; Eder C.

449 Lima: Writing- Reviewing and Editing,

$450 \quad$ Funding

451 The authors are grateful for the financial supports from the Engineering and Physical Sciences

452 Research Council (EPSRC) UK.

\section{Competing Interests}

454 The authors declare that they have no known competing financial interests or personal 455 relationships that could have appeared to influence the work reported in this paper.

456 Availability of data and materials

457 Not applicable

\section{References}

459 Baierle, F., John, D. K., Souza, M. P., Bjerk, T. R., Moraes, M. S., Hoeltz, M., . . Schneider, R. C. 460 (2015). Biomass from microalgae separation by electroflotation with iron and aluminum 461 spiral electrodes. Chemical Engineering Journal, 267, 274-281.

462 Bazrafshan, E., Alipour, M. R., \& Mahvi, A. H. (2016). Textile wastewater treatment by application 463 of combined chemical coagulation, electrocoagulation, and adsorption processes. Desalination and Water Treatment, 57(20), 9203-9215. (SPAC) for efficient removal of micropollutants from wastewater treatment plant effluent. Water research, 90, 90-99. 
Chou, W.-L., Wang, C.-T., \& Chang, S.-Y. (2009). Study of COD and turbidity removal from real oxide-CMP wastewater by iron electrocoagulation and the evaluation of specific energy consumption. Journal of hazardous materials, 168(2-3), 1200-1207.

Devlin, T. R., Kowalski, M. S., Pagaduan, E., Zhang, X., Wei, V., \& Oleszkiewicz, J. A. (2019). Electrocoagulation of wastewater using aluminum, iron, and magnesium electrodes. Journal of hazardous materials, 368, 862-868.

Dudziak, M., Wyczarska-Kokot, J., Łaskawiec, E., \& Stolarczyk, A. (2019). Application of Ultrafiltration in a Swimming Pool Water Treatment System. Membranes, 9(3), 44.

Elazzouzi, M., El Kasmi, A., Haboubi, K., \& Elyoubi, M. (2018). A novel electrocoagulation process using insulated edges of Al electrodes for enhancement of urban wastewater treatment: Techno-economic study. Process Safety and Environmental Protection, 116, 506-515.

Ensano, B. M. B., Borea, L., Naddeo, V., Belgiorno, V., de Luna, M. D. G., Balakrishnan, M., \& Ballesteros Jr, F. C. (2019). Applicability of the electrocoagulation process in treating real municipal wastewater containing pharmaceutical active compounds. Journal of hazardous materials, 361, 367-373.

Eryuruk, K., Un, U. T., \& Ogutveren, U. B. (2018). Electrochemical treatment of wastewaters from poultry slaughtering and processing by using iron electrodes. Journal of cleaner production, 172, 1089-1095.

Hashim, K. S., Al Khaddar, R., Jasim, N., Shaw, A., Phipps, D., Kot, P., . . Alawsh, R. (2019). Electrocoagulation as a green technology for phosphate removal from River water. Separation and Purification Technology, 210, 135-144.

Heidmann, I., \& Calmano, W. (2010). Removal of Ni, Cu and $\mathrm{Cr}$ from a galvanic wastewater in an electrocoagulation system with Fe-and Al-electrodes. Separation and Purification Technology, 71(3), 308-314.

Izadi, A., Hosseini, M., Darzi, G. N., Bidhendi, G. N., \& Shariati, F. P. (2018). Treatment of paperrecycling wastewater by electrocoagulation using aluminum and iron electrodes. Journal of Environmental Health Science and Engineering, 16(2), 257-264.

Kårelid, V., Larsson, G., \& Björlenius, B. (2017). Effects of recirculation in a three-tank pilot-scale system for pharmaceutical removal with powdered activated carbon. Journal of environmental management, 193, 163-171.

Katal, R., \& Pahlavanzadeh, H. (2011). Influence of different combinations of aluminum and iron electrode on electrocoagulation efficiency: Application to the treatment of paper mill wastewater. Desalination, 265(1-3), 199-205.

Lee, S. Y., \& Gagnon, G. A. (2016). Comparing the growth and structure of flocs from electrocoagulation and chemical coagulation. Journal of Water Process Engineering, 10, 20-29.

Mahmad, M. K. N., Rozainy, M. M. R., Abustan, I., \& Baharun, N. (2016). Electrocoagulation process by using aluminium and stainless steel electrodes to treat total chromium, colour and turbidity. Procedia Chemistry, 19, 681-686.

Mailler, R., Gasperi, J., Coquet, Y., Deshayes, S., Zedek, S., Cren-Olivé, C., . . Caupos, E. (2015). Study of a large scale powdered activated carbon pilot: Removals of a wide range of emerging and priority micropollutants from wastewater treatment plant effluents. Water research, 72, 315-330. 
Table 1. Characteristic of wastewater from secondary sedimentation tank.

\begin{tabular}{lc}
\hline \multicolumn{1}{c}{ Variable } & Values \\
\hline $\mathrm{pH}$ & $7.03-7.21$ \\
Conductivity $(\mu \mathrm{S} / \mathrm{cm})$ & $850-1100$ \\
Suspended solids $(\mathrm{mg} / \mathrm{L})$ & $1.4-6.6$ \\
COD $(\mathrm{mg} / \mathrm{L})$ & 20 \\
Total Phosphorous $(\mathrm{mg} / \mathrm{L})$ & 0.45 \\
Total Nitrogen $(\mathrm{mg} / \mathrm{L})$ & 11.5 \\
\hline
\end{tabular}

Omwene, P. I., Kobya, M., \& Can, O. T. (2018). Phosphorus removal from domestic wastewater in electrocoagulation reactor using aluminium and iron plate hybrid anodes. Ecological engineering, 123, 65-73.

Papadopoulos, K. P., Argyriou, R., Economou, C. N., Charalampous, N., Dailianis, S., Tatoulis, T. I., ... Vayenas, D. V. (2019). Treatment of printing ink wastewater using electrocoagulation. Journal of environmental management, 237, 442-448.

Peng, C., Zhai, Y., Zhu, Y., Xu, B., Wang, T., Li, C., \& Zeng, G. (2016). Production of char from sewage sludge employing hydrothermal carbonization: char properties, combustion behavior and thermal characteristics. Fuel, 176, 110-118.

Sahu, O., Mazumdar, B., \& Chaudhari, P. (2019). Electrochemical treatment of sugar industry wastewater: process optimization by response surface methodology. International journal of environmental science and technology, 16(3), 1527-1540.

Sasson, M. B., Calmano, W., \& Adin, A. (2009). Iron-oxidation processes in an electroflocculation (electrocoagulation) cell. Journal of Hazardous Materials, 171(1-3), 704-709.

Sher, F., Hanif, K., Iqbal, S. Z., \& Imran, M. (2020). Implications of advanced wastewater treatment: Electrocoagulation and electroflocculation of effluent discharged from a wastewater treatment plant. Journal of Water Process Engineering, 33, 101101.

Tanyol, M., Ogedey, A., \& Oguz, E. (2018). COD removal from leachate by electrocoagulation process: treatment with monopolar electrodes in parallel connection. Water Science and Technology, 77(1), 177-186.

Yavuz, Y., \& Ögütveren, Ü. (2018). Treatment of industrial estate wastewater by the application of electrocoagulation process using iron electrodes. Journal of environmental management, 207, 151-158.

Zodi, S., Potier, O., Lapicque, F., \& Leclerc, J.-P. (2009). Treatment of the textile wastewaters by electrocoagulation: Effect of operating parameters on the sludge settling characteristics. Separation and purification Technology, 69(1), 29-36.

\section{List of Tables}


Table 2. Properties of powdered activated carbon.

Parameters

Total surface area $\left(\mathrm{m}^{2} / \mathrm{g}\right)$

Bulk density $\left(\mathrm{kg} / \mathrm{m}^{3}\right)$

Particle size range $(\mathrm{mm})$

Mean pore radius (A)

Iodine number

Abrasion number

Ash (\%)

Moisture (\%)

\section{Activated carbon}

800-1800

$360-740$

5-50

$20-40$

800-1200

$70-80$

6

$3-10$

543

544 
Table 3. Settings of EC reactor via $\mathrm{Fe}$ and $\mathrm{Al}$ treatment.

\begin{tabular}{cccc}
\hline Electrodes & \multicolumn{3}{c}{ Parameter settings } \\
\cline { 2 - 4 } $\mathrm{Fe}$ & Current (A) & Voltage (V) & PAC (mg) \\
& 1 & 38 & 20 \\
$\mathrm{Al}$ & 2 & 58 & 20 \\
& 0.5 & 26 & 20 \\
& 0.75 & 37 & 20 \\
& 1 & 58 & 20 \\
\hline
\end{tabular}


$550 \quad$ Table 4. SVI of sludge produced by $\mathrm{Al}$ and $\mathrm{Fe}$ electrodes operation with wastewater.

\begin{tabular}{cccccc}
\hline $\begin{array}{c}\text { Electrode } \\
\text { type }\end{array}$ & $\begin{array}{c}\text { Current } \\
\text { (A) }\end{array}$ & $\begin{array}{c}\text { Current density } \\
\left(\mathrm{A} / \mathrm{m}^{2}\right)\end{array}$ & $\begin{array}{c}\text { MLSS } \\
(\mathrm{mg} / \mathrm{L})\end{array}$ & $\begin{array}{c}\text { Settled volume of } \\
\text { sludge }(\mathrm{mL} / \mathrm{L})\end{array}$ & $\begin{array}{c}\text { SVI } \\
(\mathrm{mL} / \mathrm{g})\end{array}$ \\
\hline $\mathrm{Al}$ & 0.5 & 0.34 & 22.2 & 0.5 & 23 \\
& 1 & 0.67 & 58 & 6 & 103 \\
& 2 & 1.34 & 86.7 & 18 & 208 \\
$\mathrm{Fe}$ & 1 & 0.67 & 22.4 & 1.3 & 58 \\
& 2 & 1.34 & 79.5 & 18 & 226 \\
& 3 & 2.02 & 131.4 & 41 & 312 \\
\hline
\end{tabular}


Table 5. Operational parameters of $\mathrm{pH}$, turbidity and conductivity.

\begin{tabular}{lccccc}
\hline \multicolumn{1}{c}{ Sample } & Setting & Current & pH & Turbidity & Conductivity \\
& & $(\mathrm{A})$ & & $(\mathrm{NTU})$ & $(\mu \mathrm{s} / \mathrm{cm})$ \\
\hline Inflow & WWPAC-Fe & - & 7.03 & 5 & 1019 \\
Outflow & WWPAC-Fe & 1 & 7.26 & 29 & 991 \\
Inflow & WWPAC-Fe & - & 7.03 & 5 & 1019 \\
Outflow & WWPAC-Fe & 2 & 7.36 & 35 & 1007 \\
Inflow & WWPAC-Al & - & 7.10 & 8 & 964 \\
Outflow & WWPAC-Al & 0.5 & 7.21 & 29 & 991 \\
Inflow & WWPAC-Al & - & 7.1 & 8 & 964 \\
Outflow & WWPAC-Al & 0.75 & 7.52 & 31 & 988 \\
Inflow & WWPAC-Al & - & 7.10 & 8 & 964 \\
Outflow & WWPAC-Al & 1 & 7.52 & 40 & 985 \\
\hline
\end{tabular}

555

556 


\section{List of Figures}

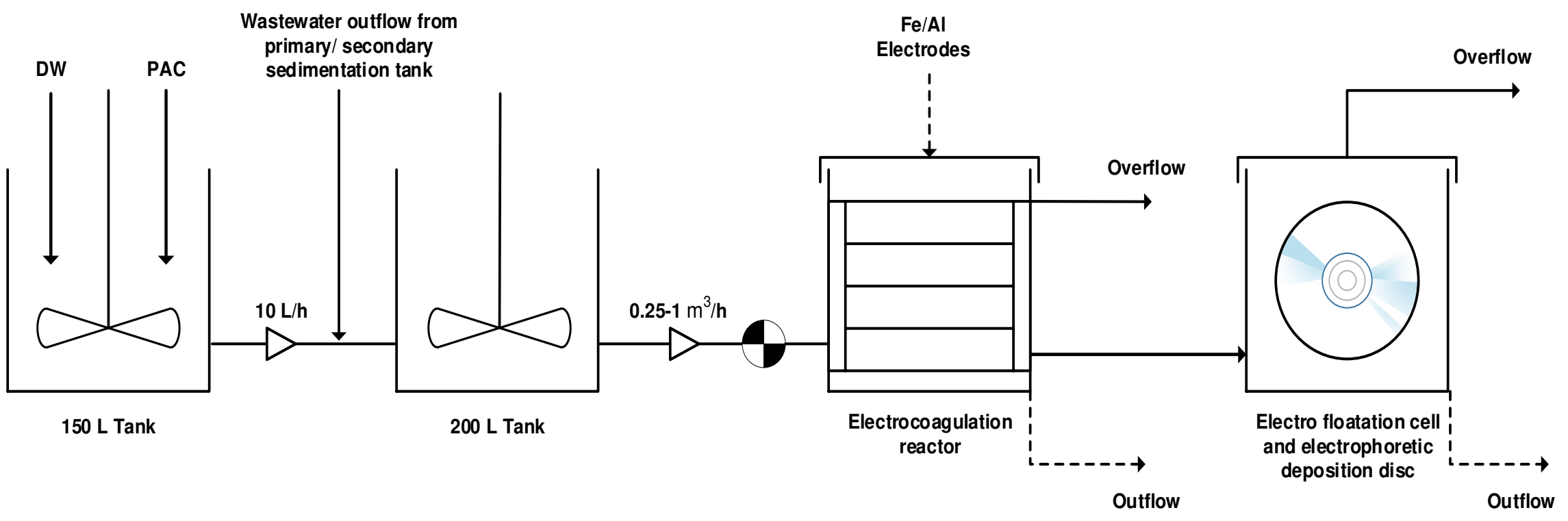

Fig. 1. Electrocoagulation pilot plant process flow diagram (PFD). 


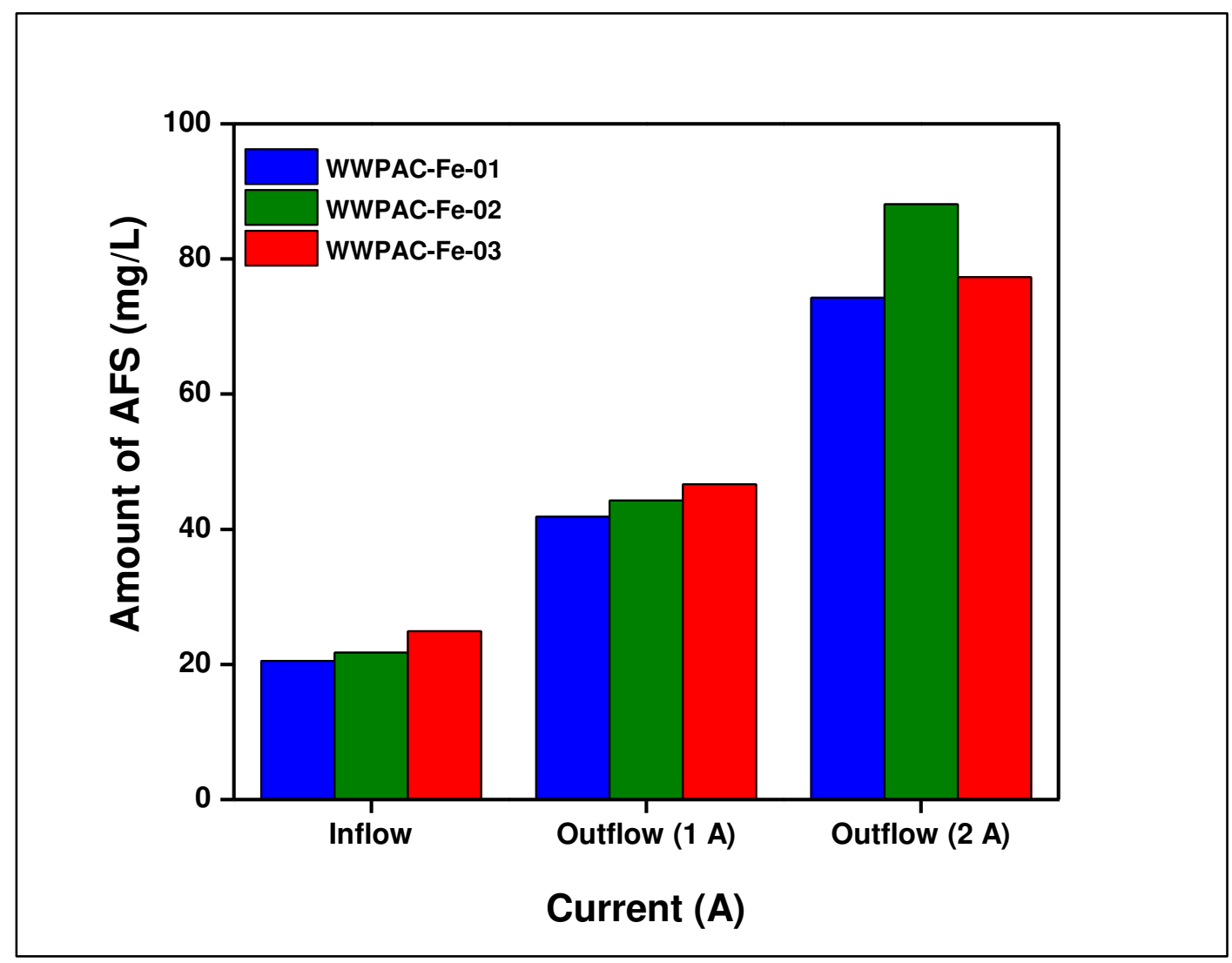

Fig. 2. Effect of current on the amount of AFS produced by Fe electrodes in combination with PAC at $500 \mathrm{~L} / \mathrm{h}$ volumetric flow rate. 


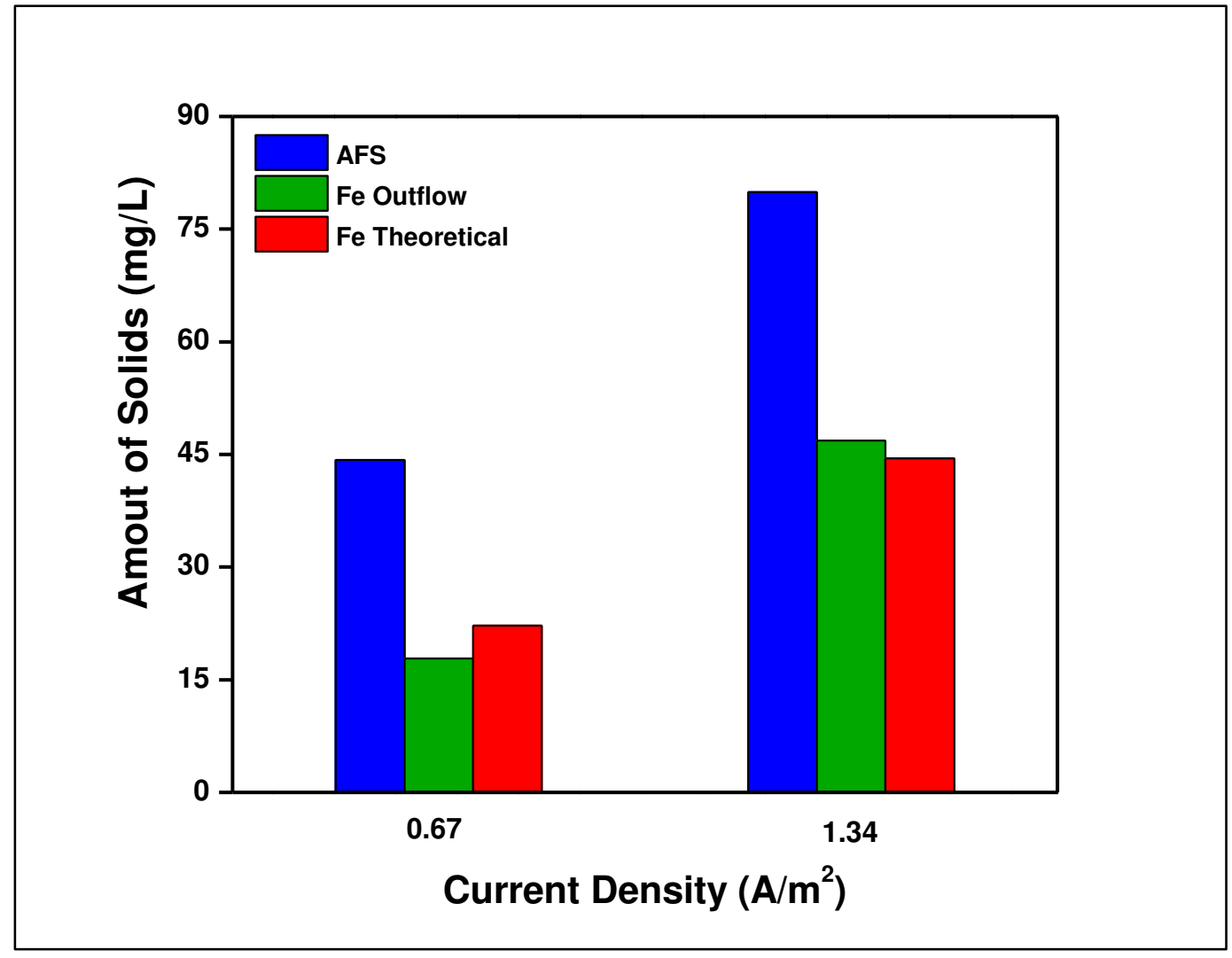

Fig. 3. Effect of current densities on the AFS, Fe coagulation dose and theoretical amount of Fe in the outflows. 


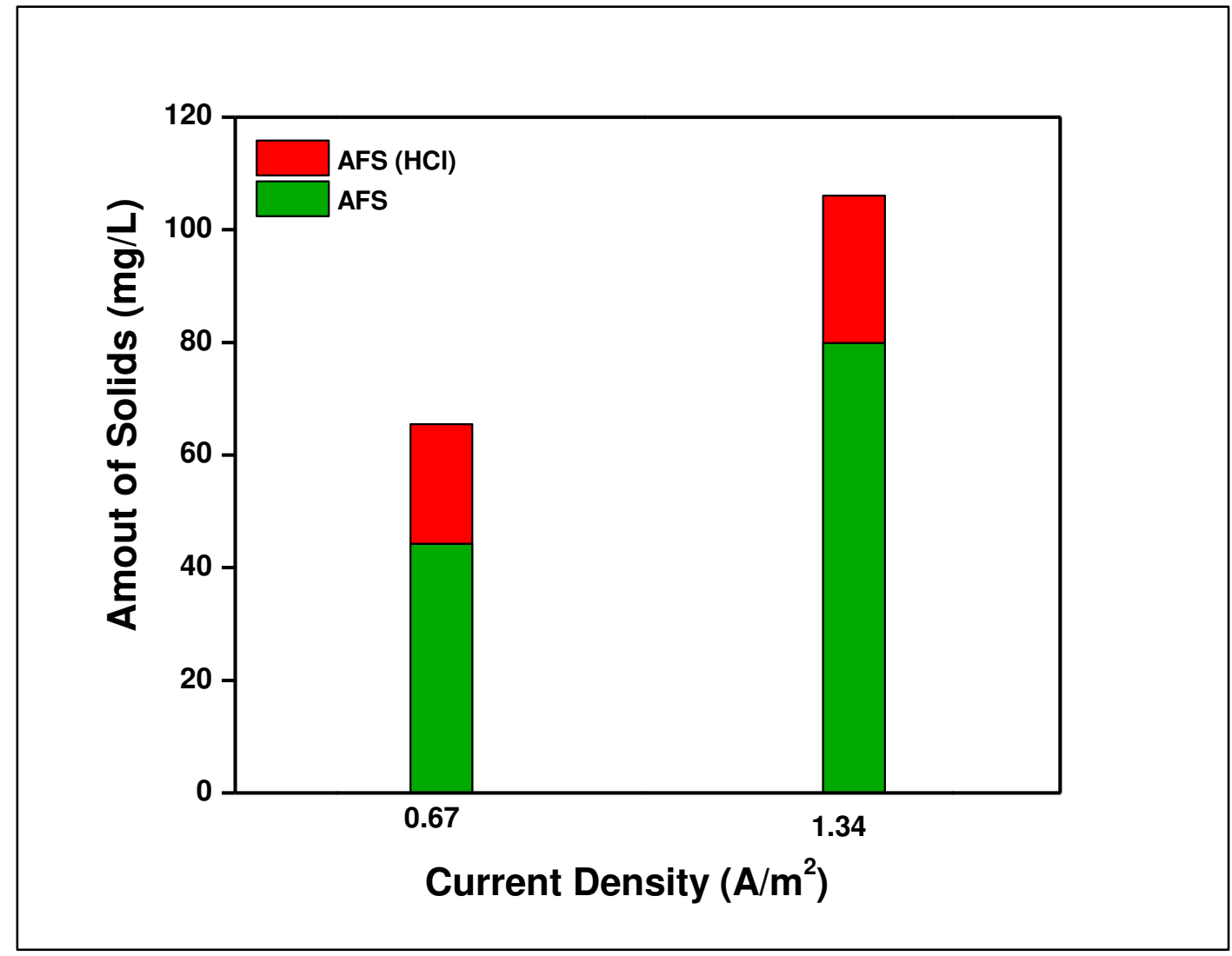

Fig 4. Amount of AFS using Fe electrodes; and after treatment of outflow with hydrochloric acid $(\mathrm{HCl})$. 


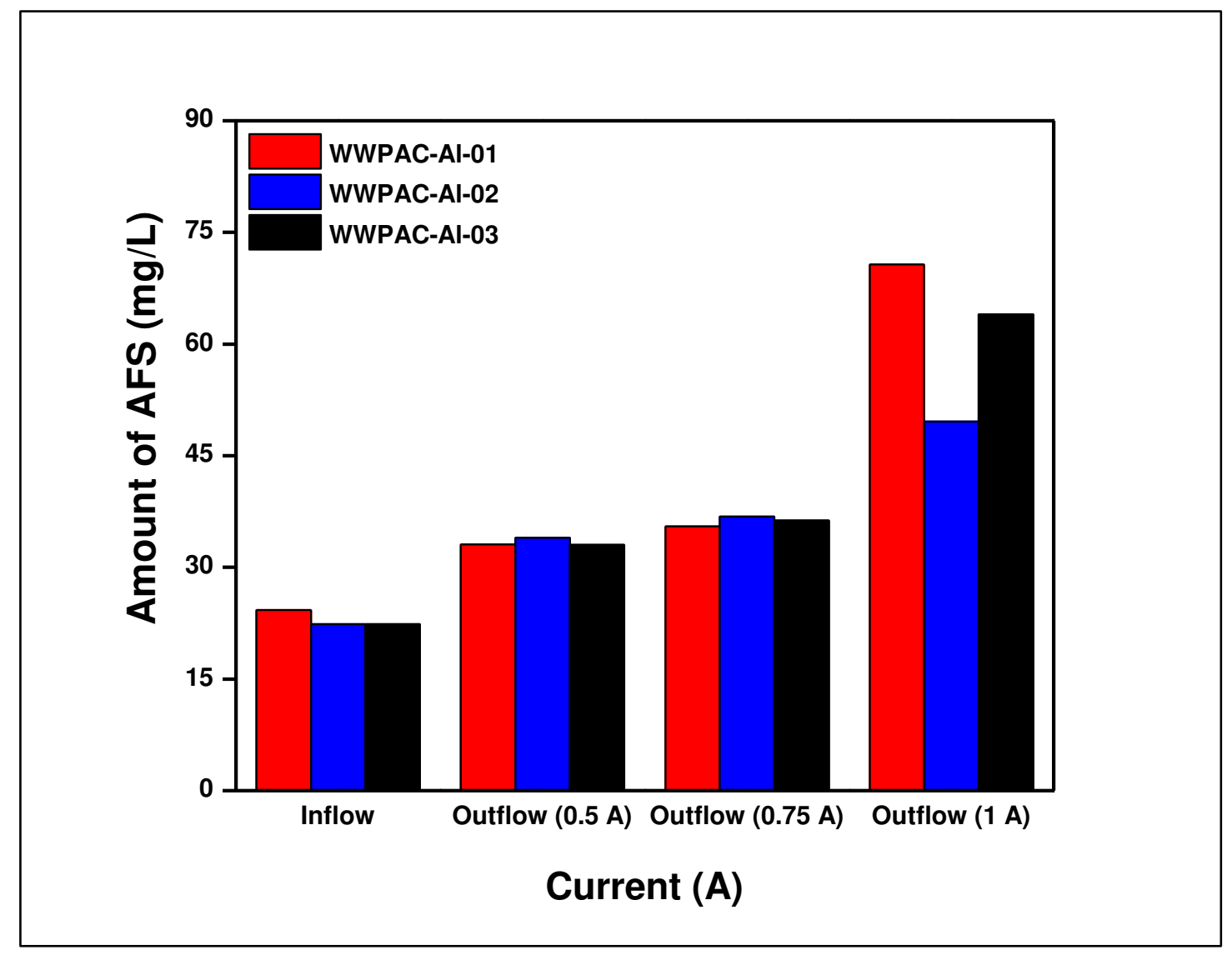

Fig. 5. Effect of current on the amount of AFS produced by Al electrodes in combination with PAC. 


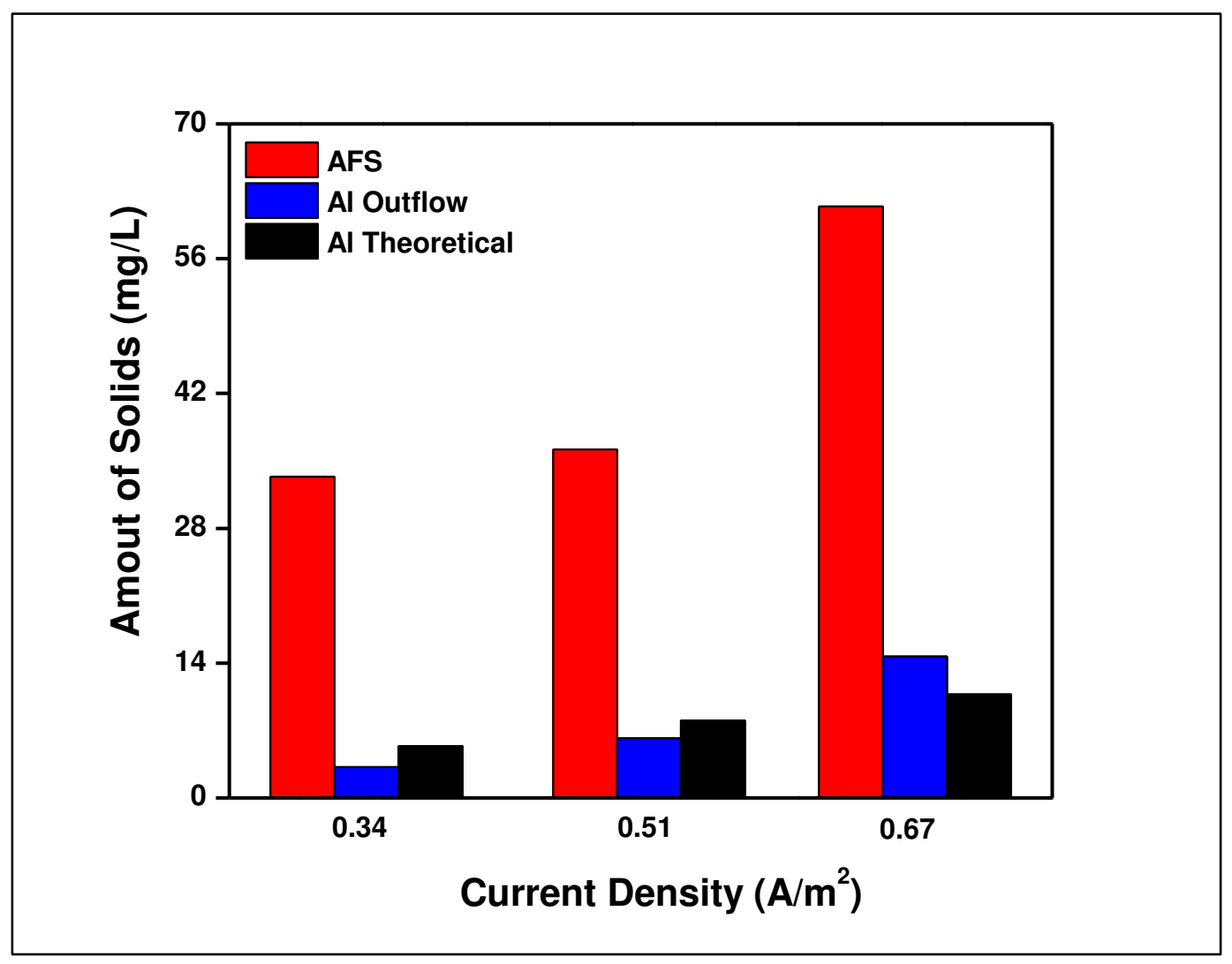

Fig. 6. Effect of current densities on the AFS, Al coagulation dose and theoretical amount of $\mathrm{Al}$ in the outflows. 


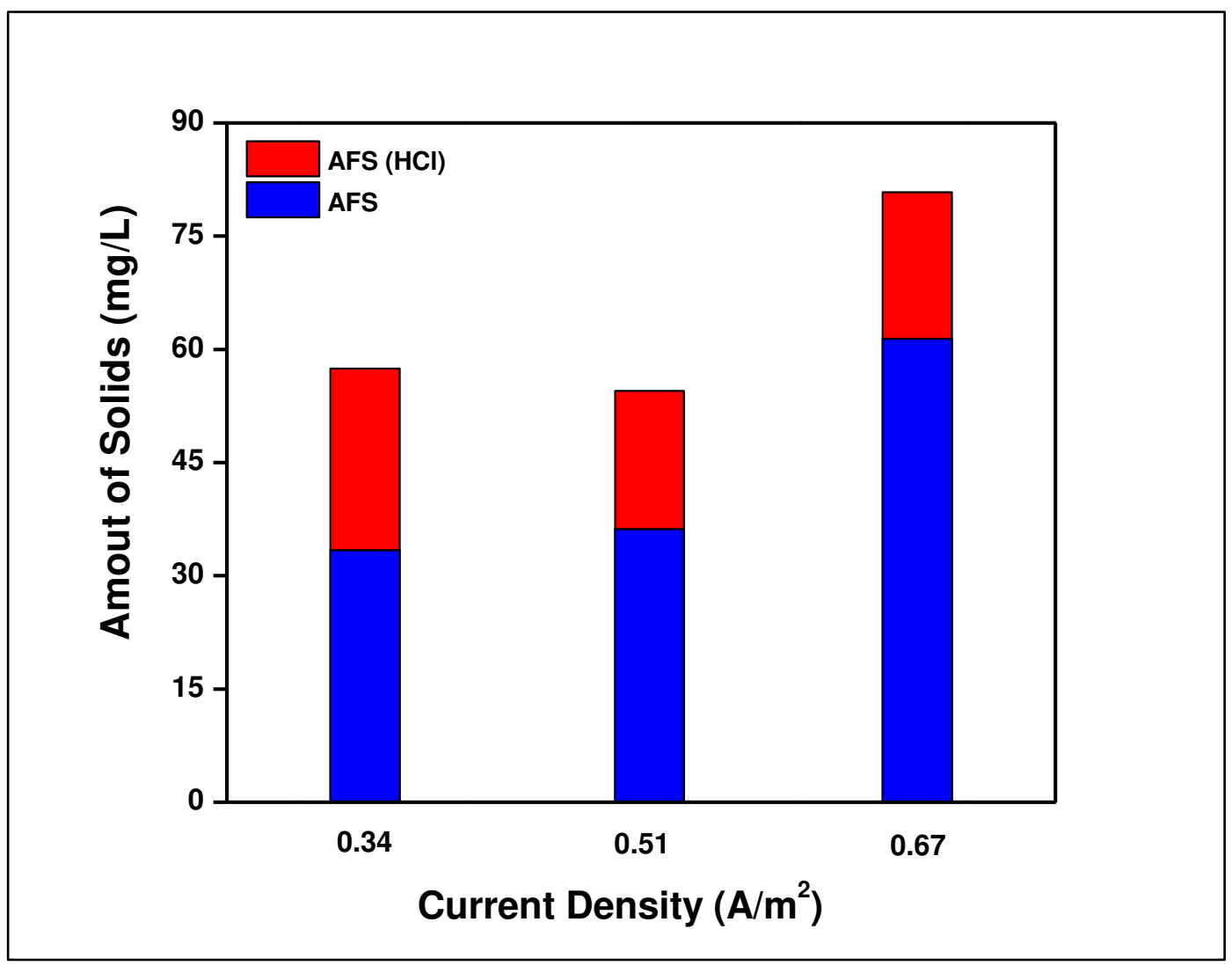

Fig. 7. Amount of AFS using Al electrodes; and after treatment of outflow with hydrochloric acid ( $\mathrm{HCl})$. 

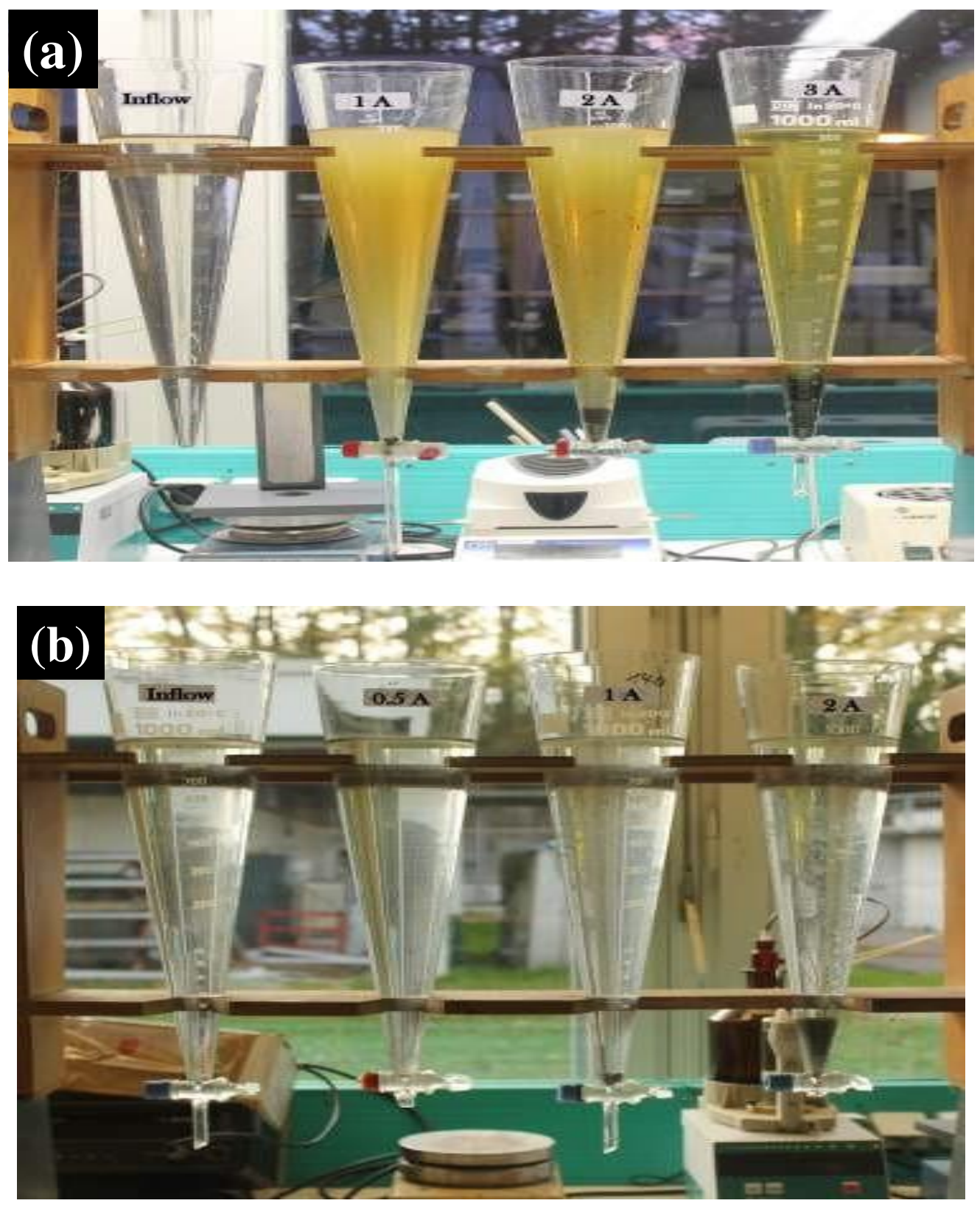

Fig. 8. Comparison of settled sludge amounts with; (a) WWPAC+Fe electrodes combination, (b) WWPAC+Al electrodes combination. 


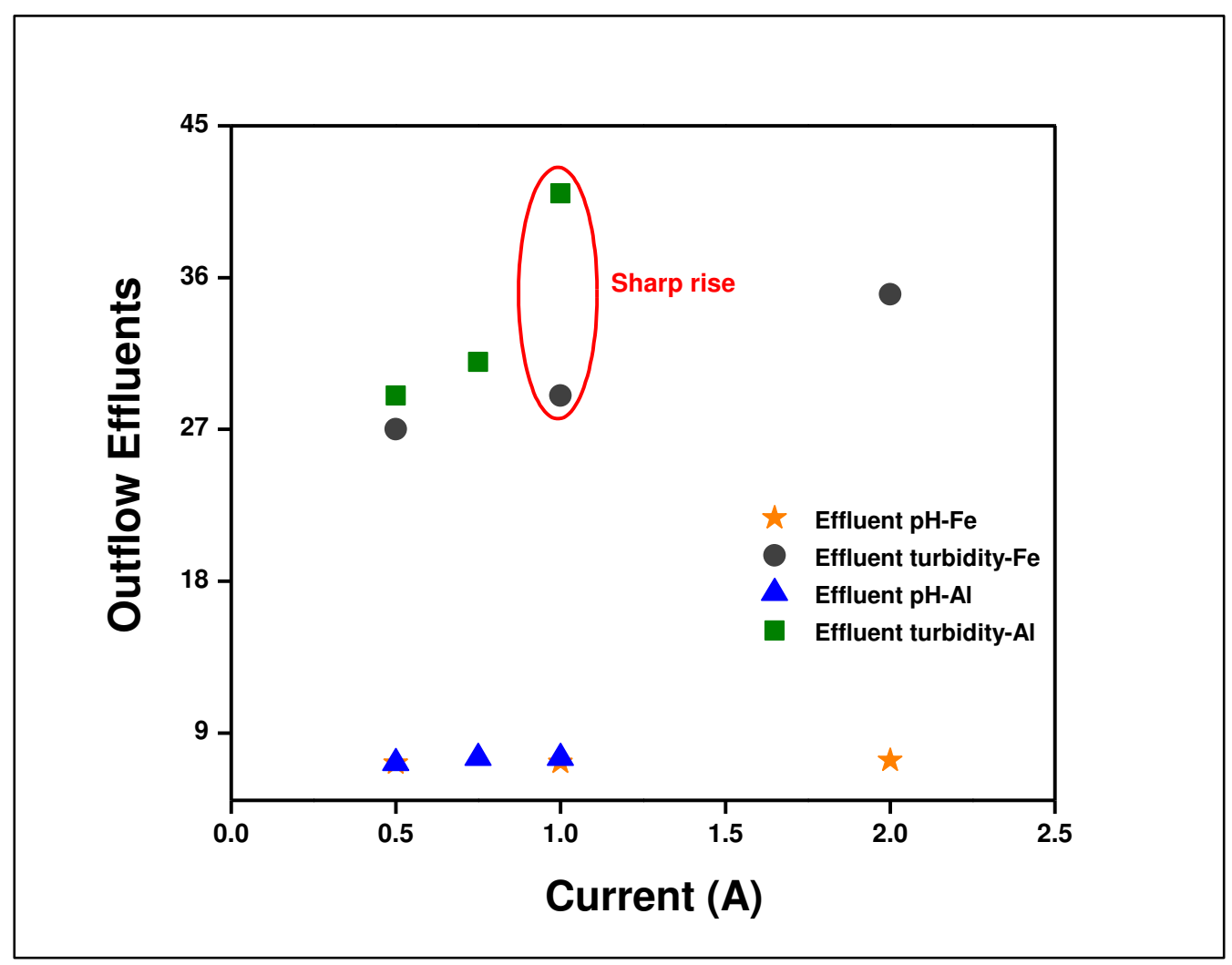

Fig. 9. Effect of applied current and electrode on the outflow's pH and turbidity (NTU). 

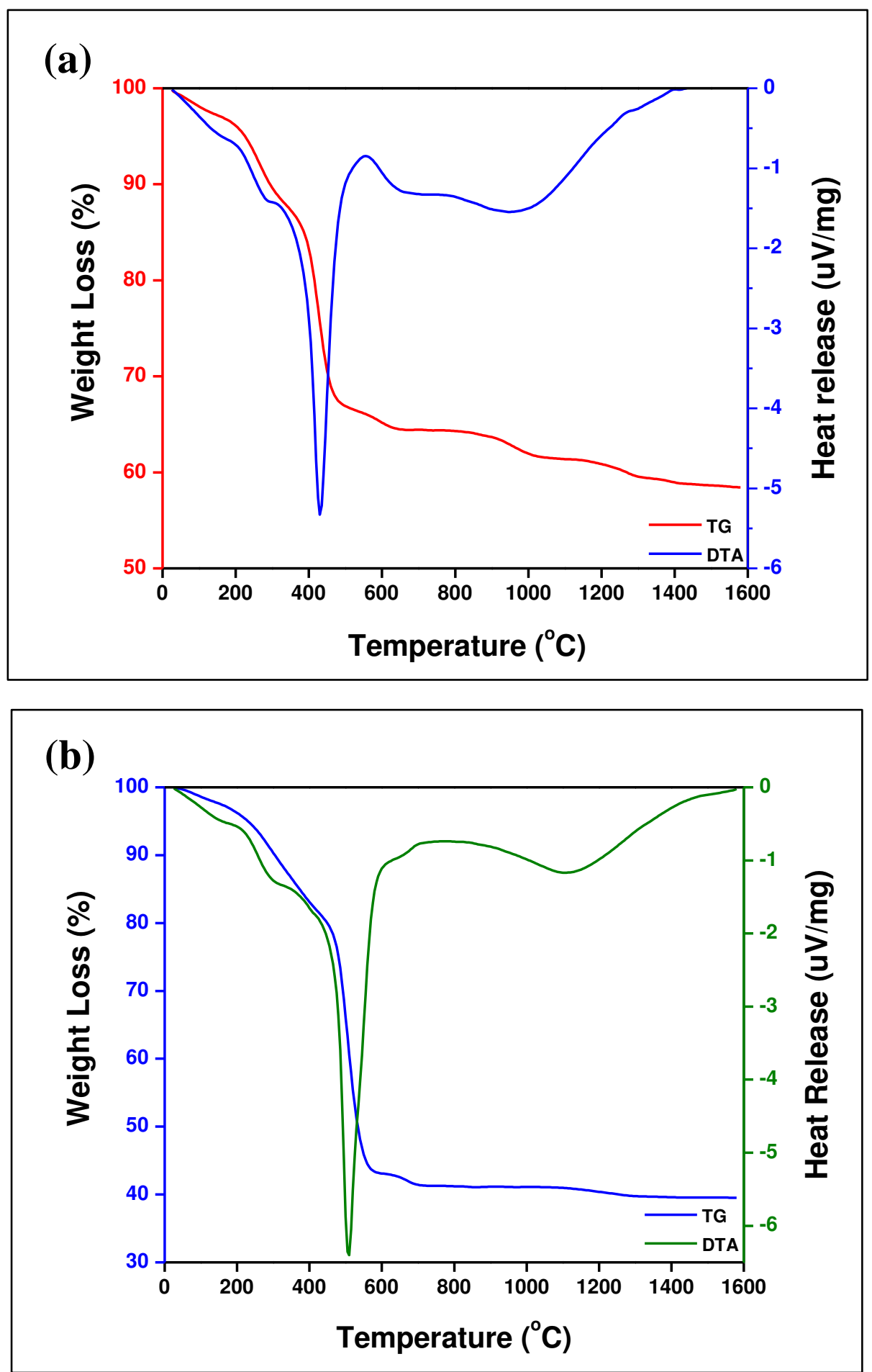

Fig. 10.TGA and DTA thermograms of flocs; (a) generated by EC process of Fe electrodes in combination with WWPAC, (b) generated by EC process of Al electrodes in combination with WWPAC. 


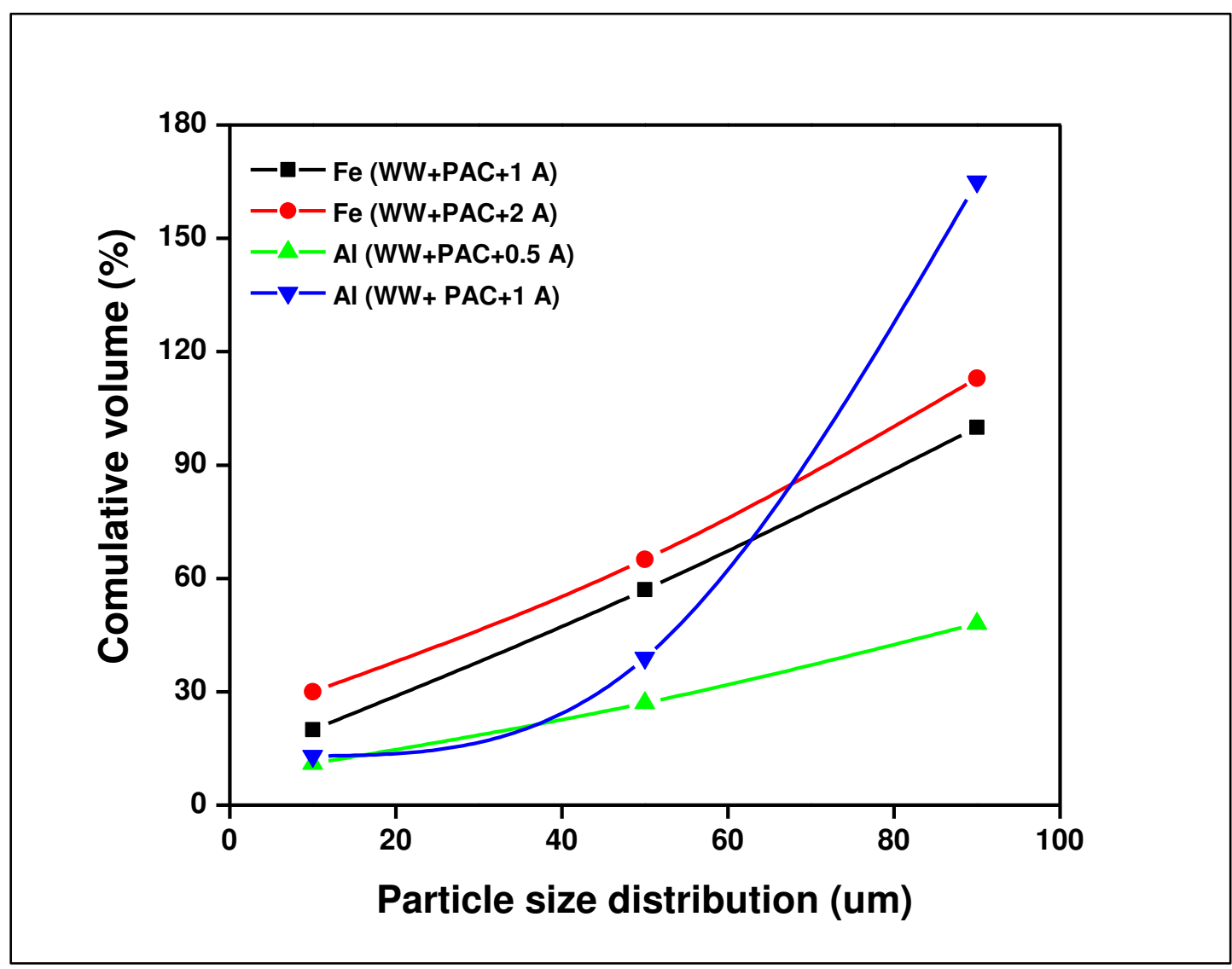

Fig. 11.The particle size distribution of flocs generated by Fe and Al EC process at different values of applied current. 
Figures

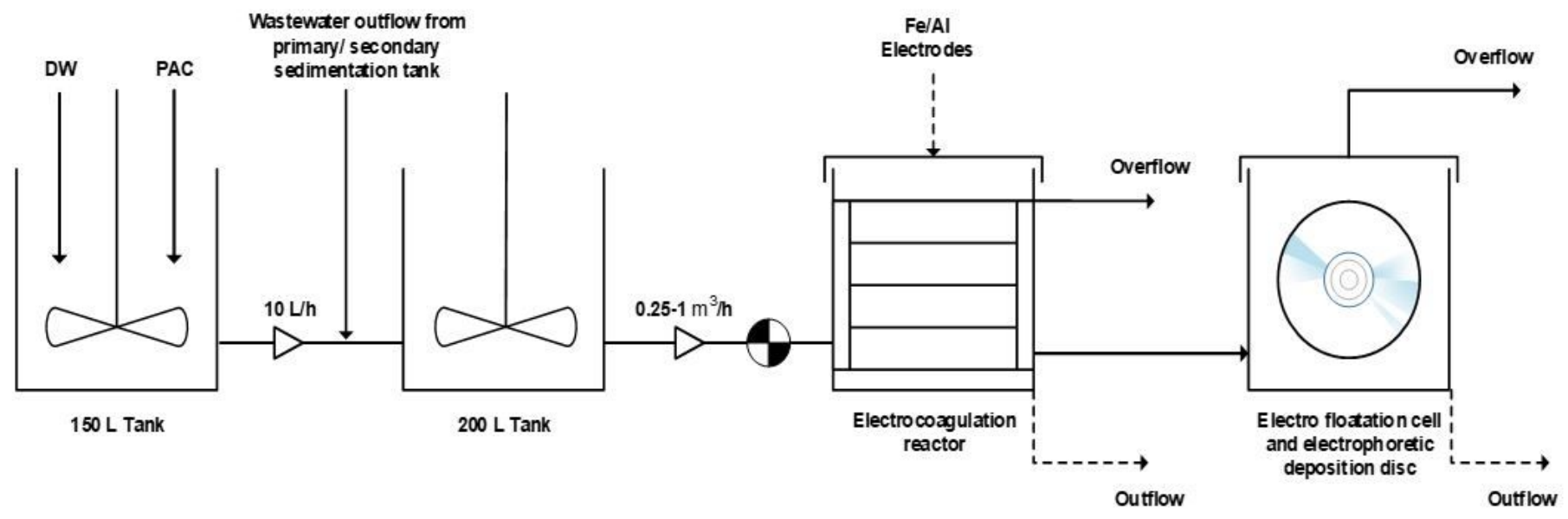

Figure 1

Electrocoagulation pilot plant process flow diagram (PFD). 


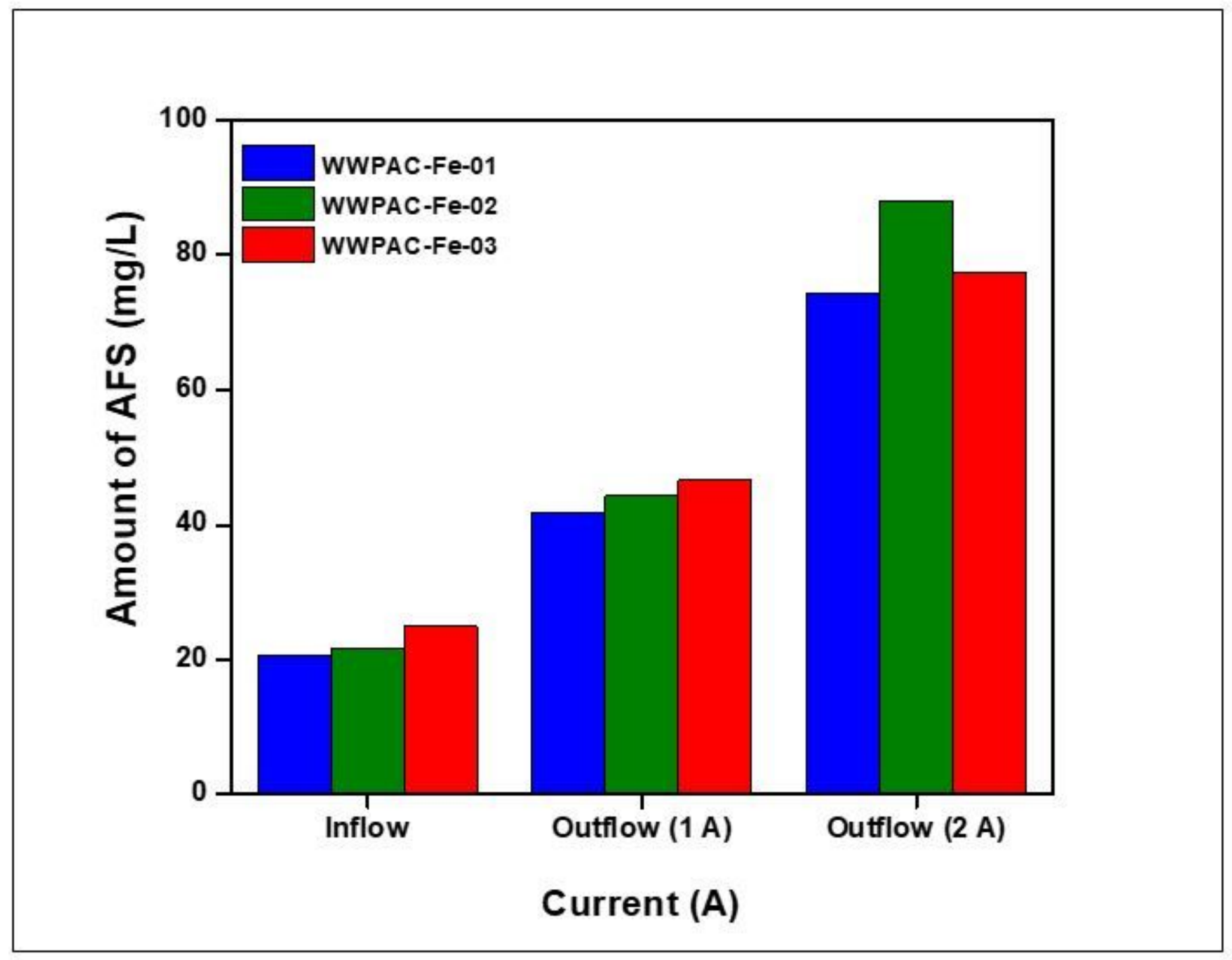

Figure 2

Effect of current on the amount of AFS produced by Fe electrodes in combination with PAC at $500 \mathrm{~L} / \mathrm{h}$ volumetric flow rate. 


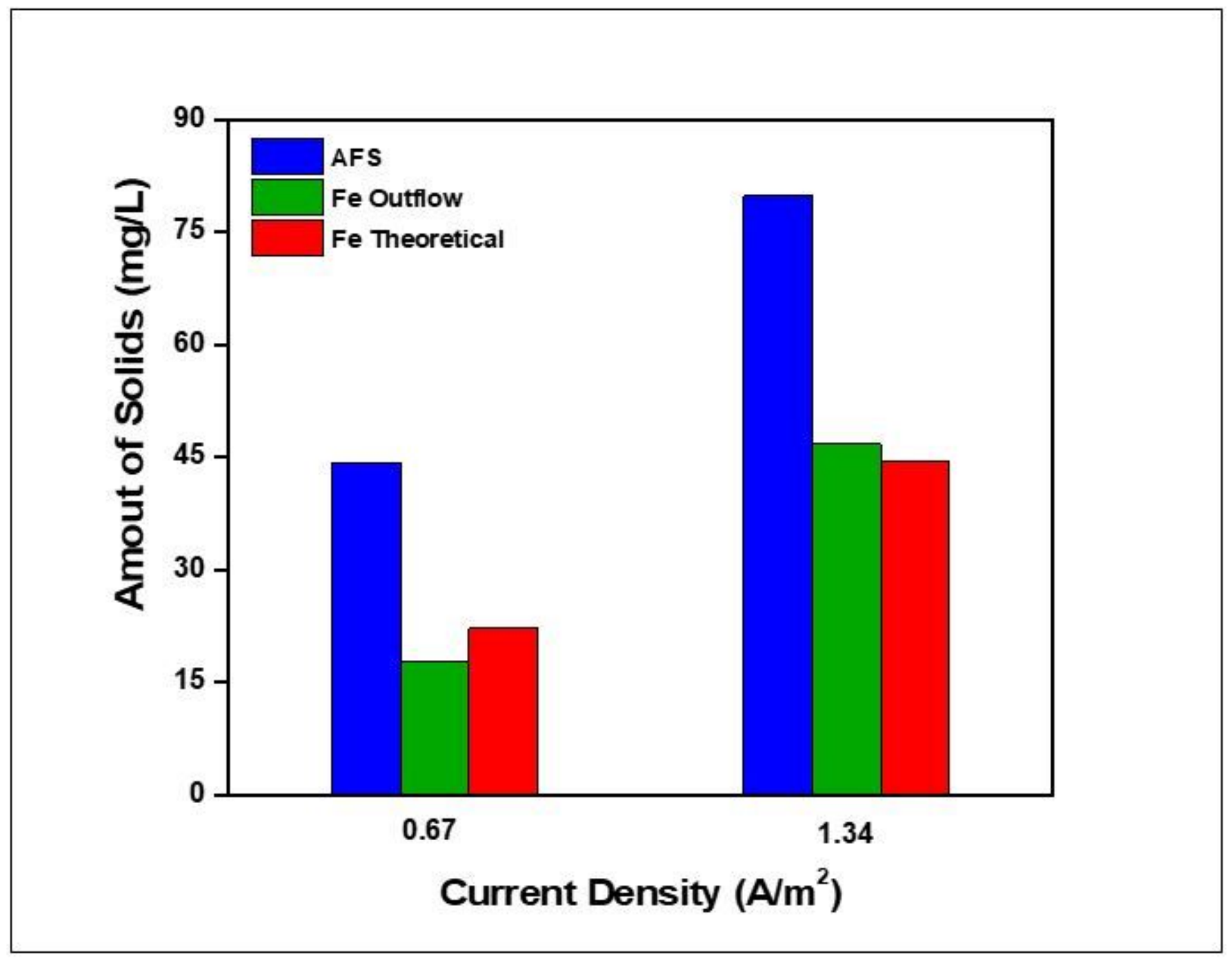

Figure 3

Effect of current densities on the AFS, Fe coagulation dose and theoretical amount of Fe in the outflows. 


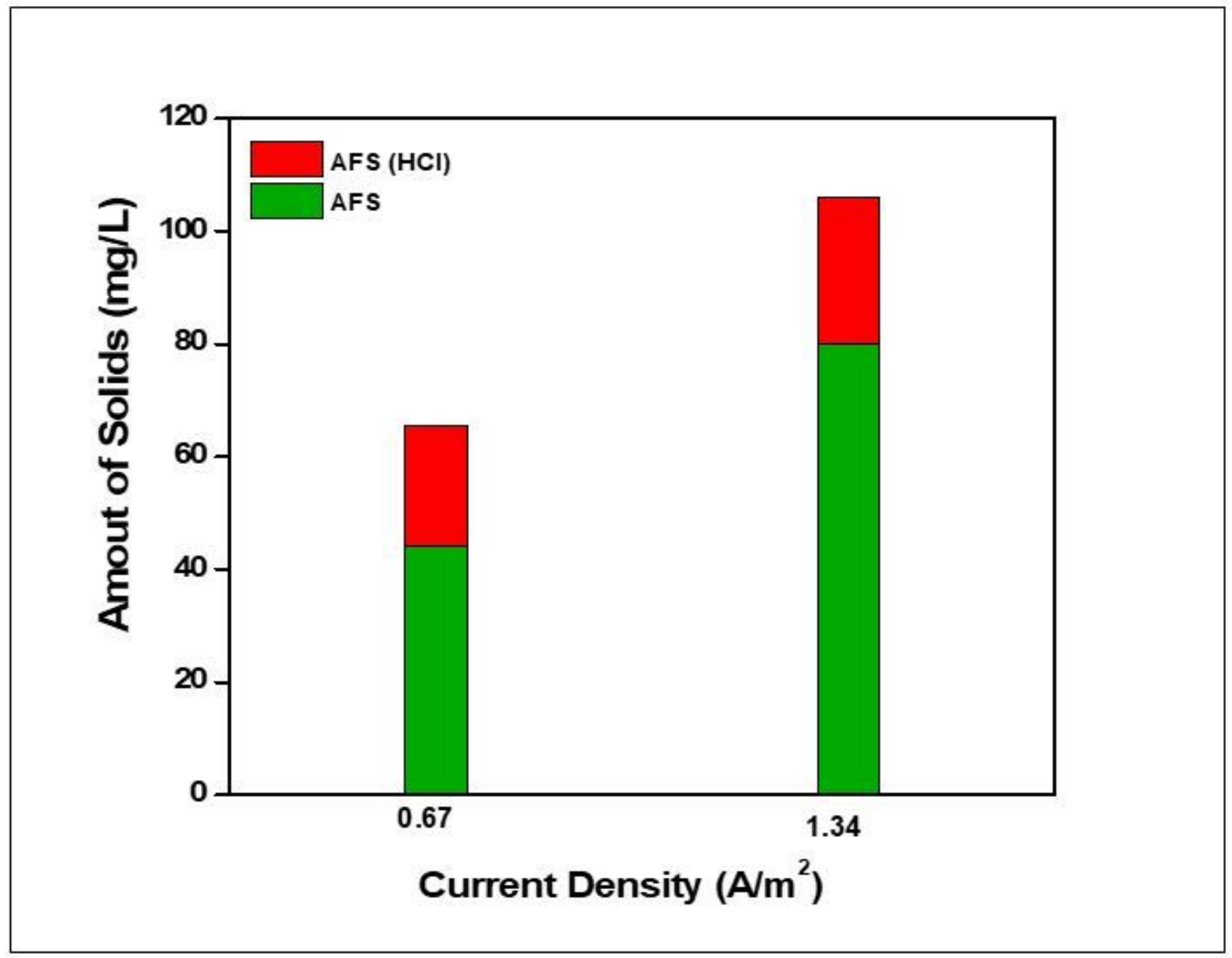

Figure 4

Amount of AFS using Fe electrodes; and after treatment of outflow with hydrochloric acid $(\mathrm{HCl})$. 


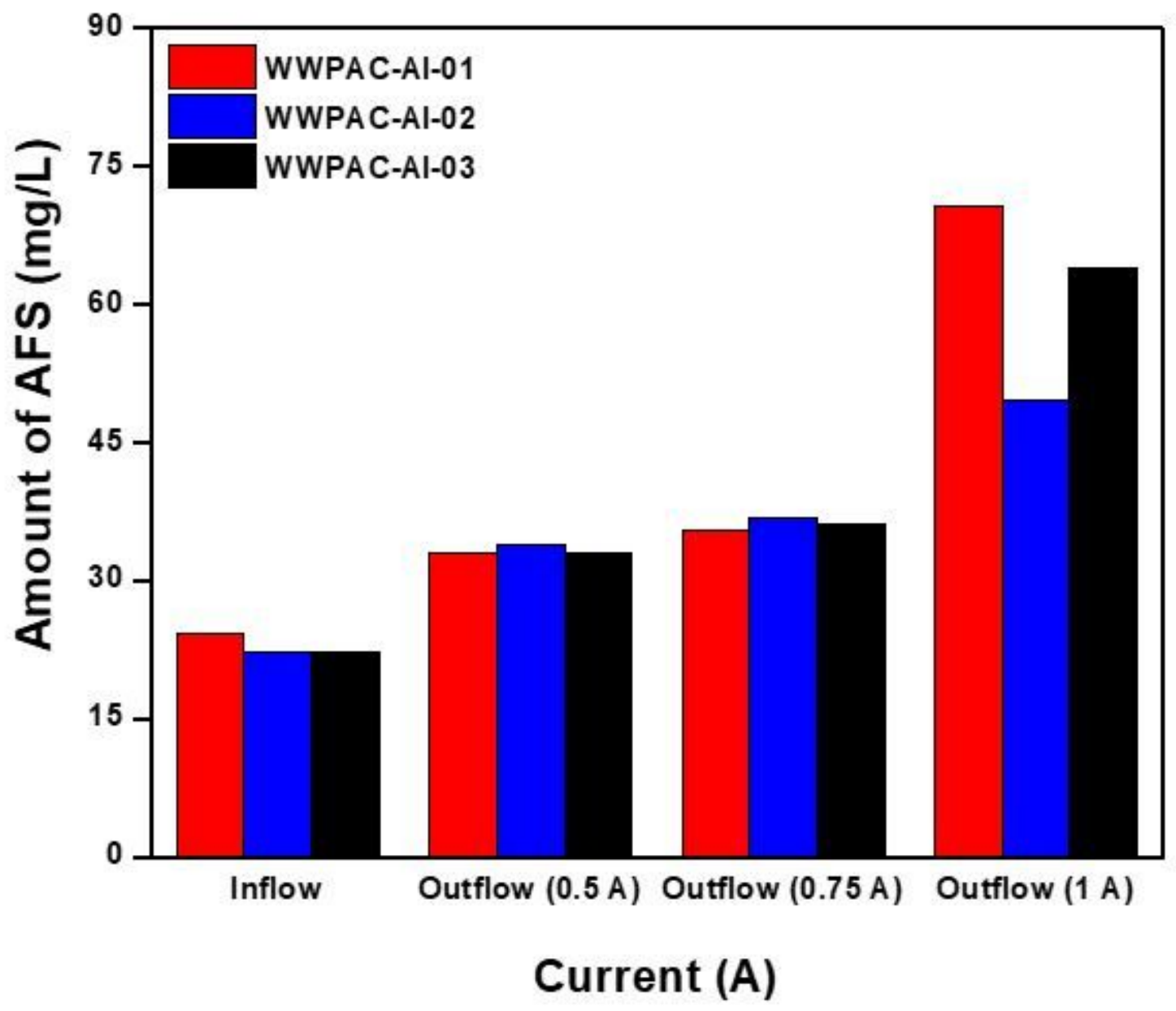

Figure 5

Effect of current on the amount of AFS produced by Al electrodes in combination with PAC. 


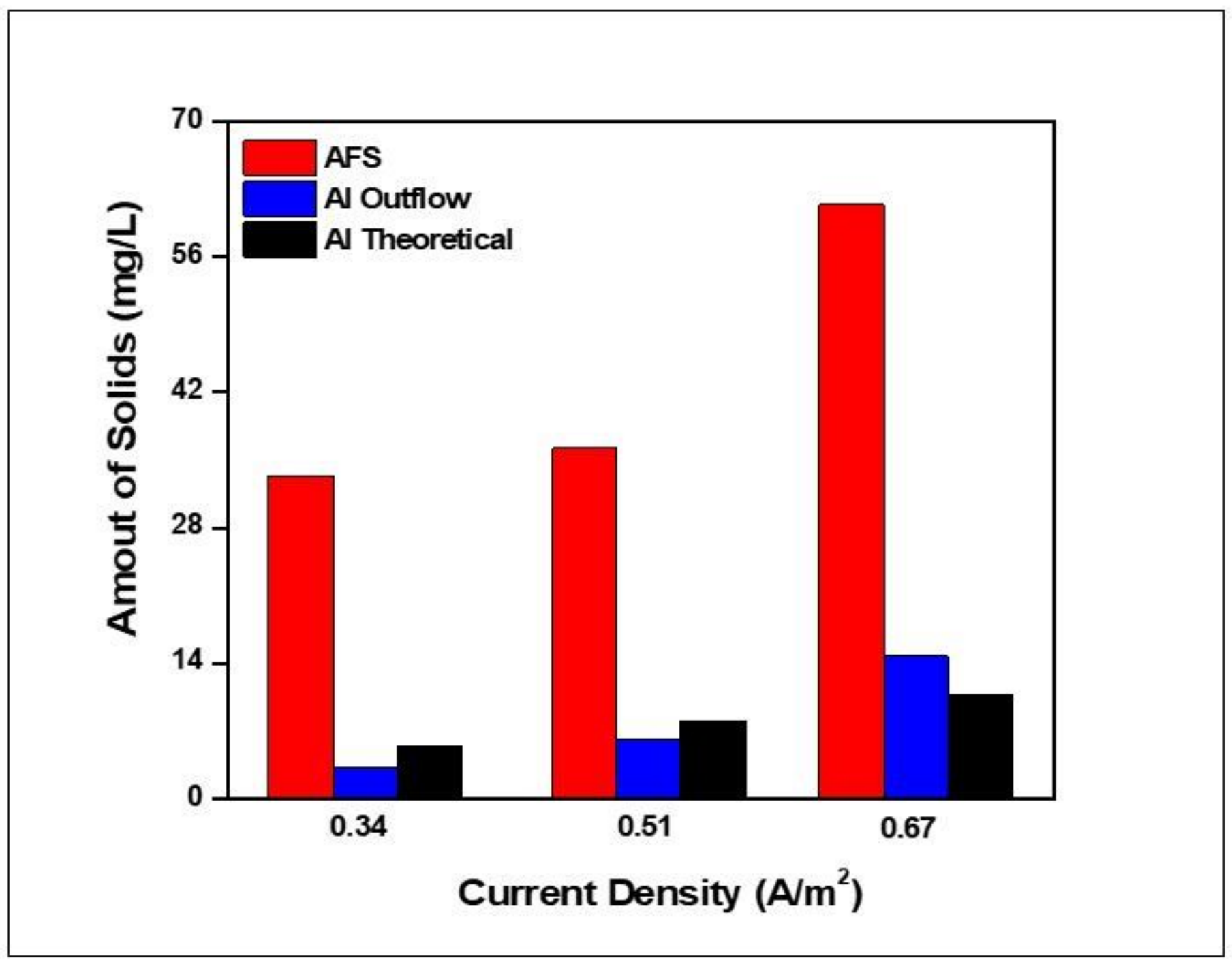

Figure 6

Effect of current densities on the AFS, Al coagulation dose and theoretical amount of Al in the outflows. 


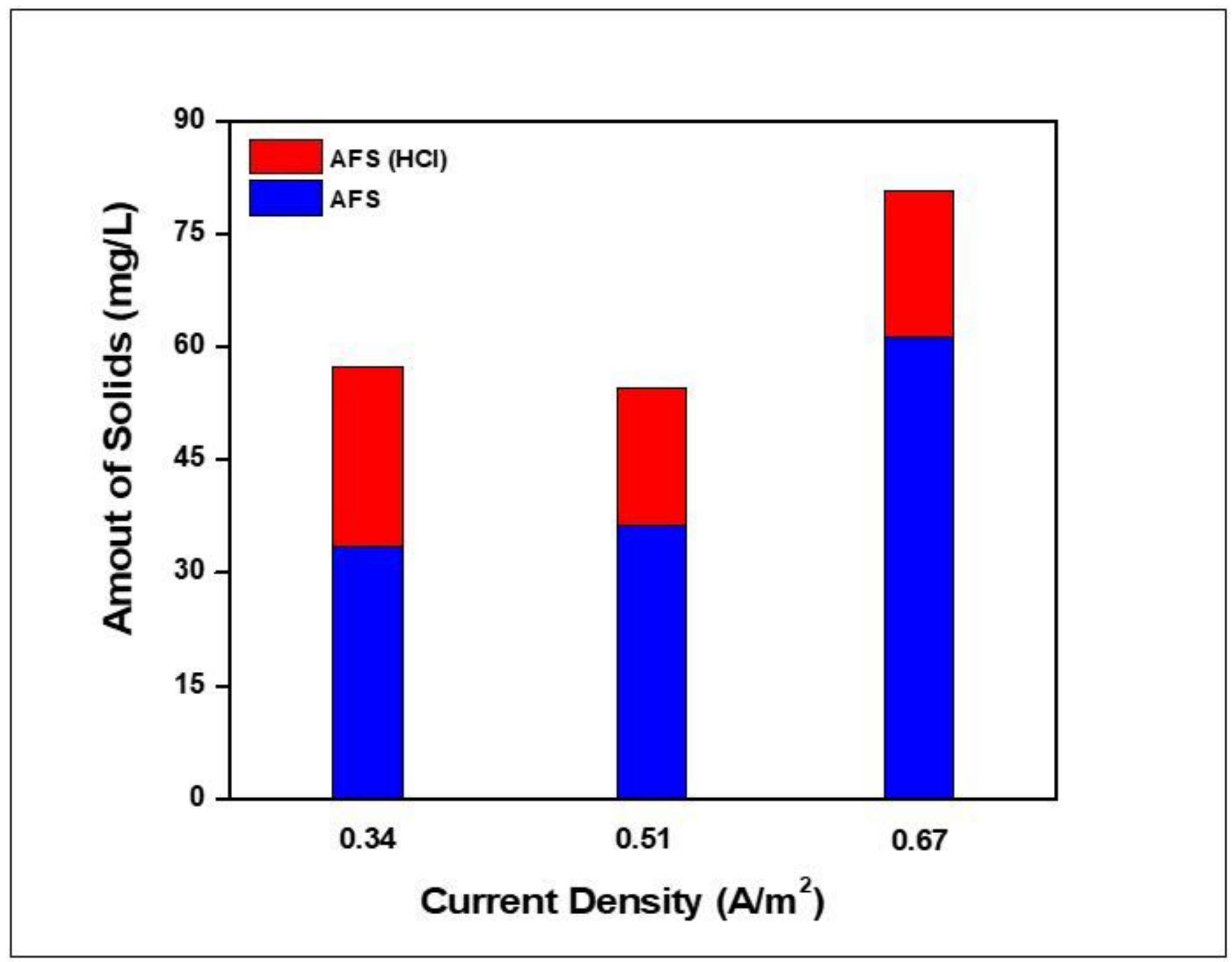

Figure 7

Amount of AFS using Al electrodes; and after treatment of outflow with hydrochloric acid $(\mathrm{HCl})$. 

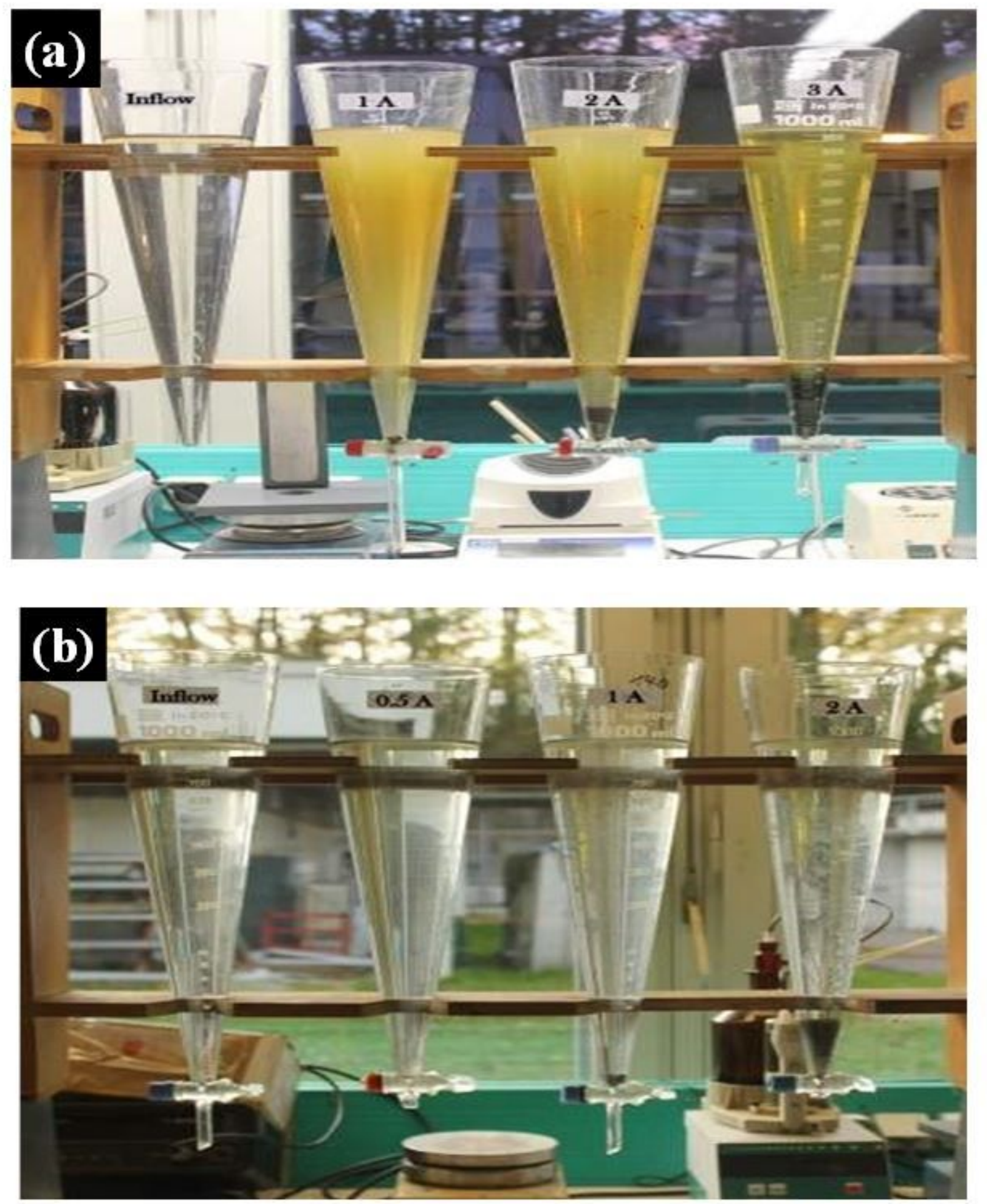

Figure 8

Comparison of settled sludge amounts with; (a) WWPAC+Fe electrodes combination, (b) WWPAC+AI electrodes combination. 


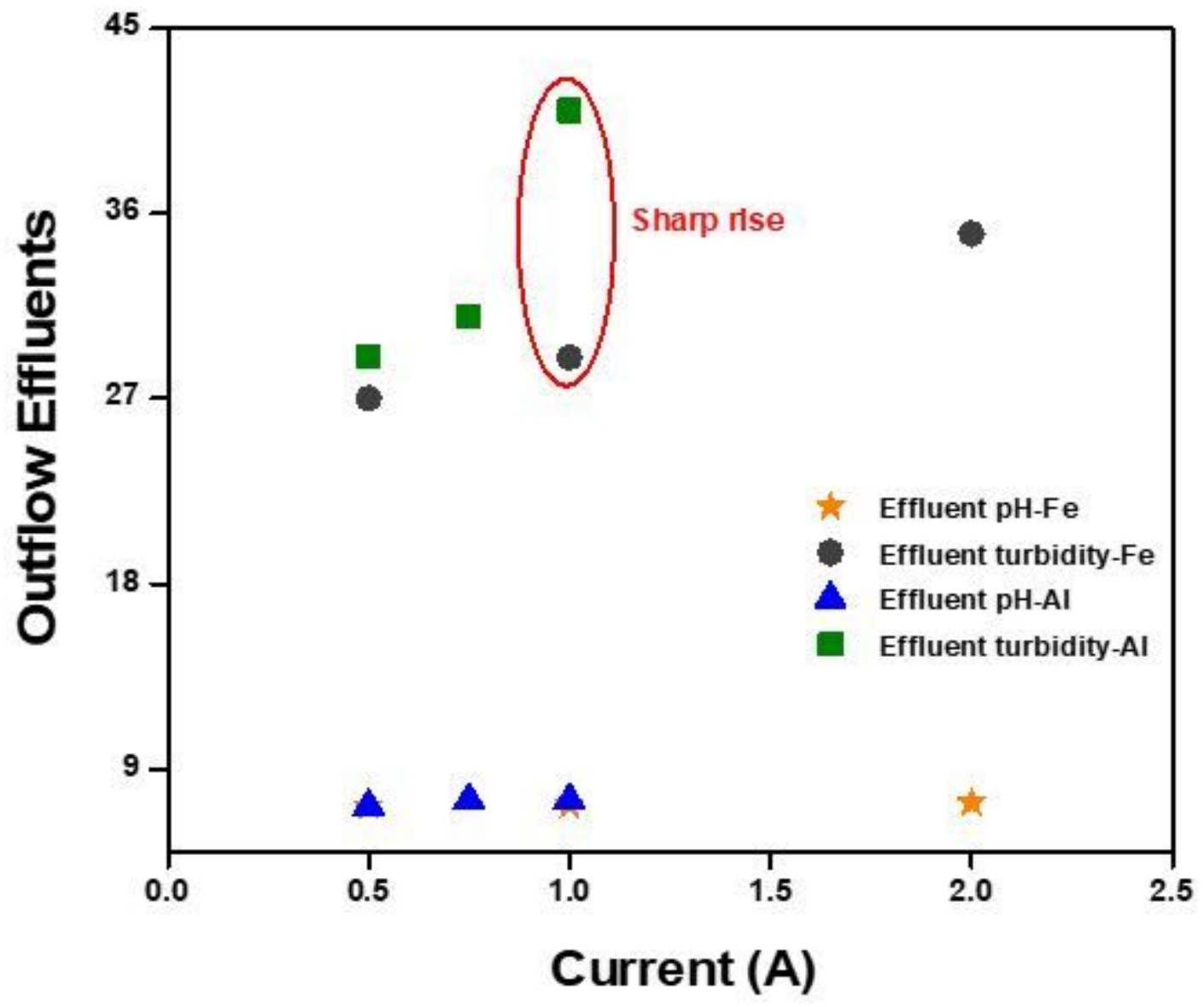

Figure 9

Effect of applied current and electrode on the outflow's pH and turbidity (NTU). 

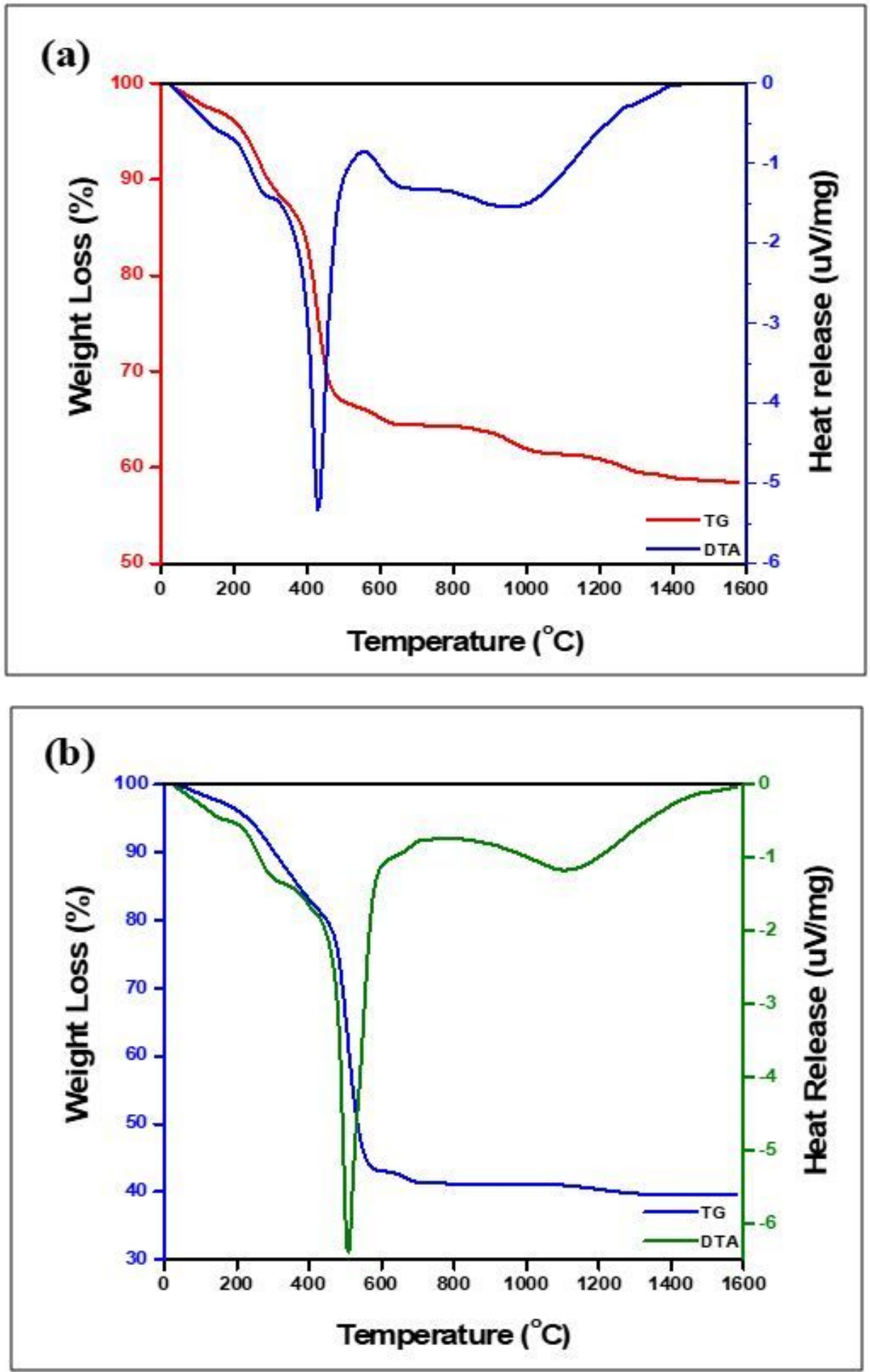

Figure 10

TGA and DTA thermograms of flocs; (a) generated by EC process of Fe electrodes in combination with WWPAC, (b) generated by EC process of Al electrodes in combination with WWPAC. 


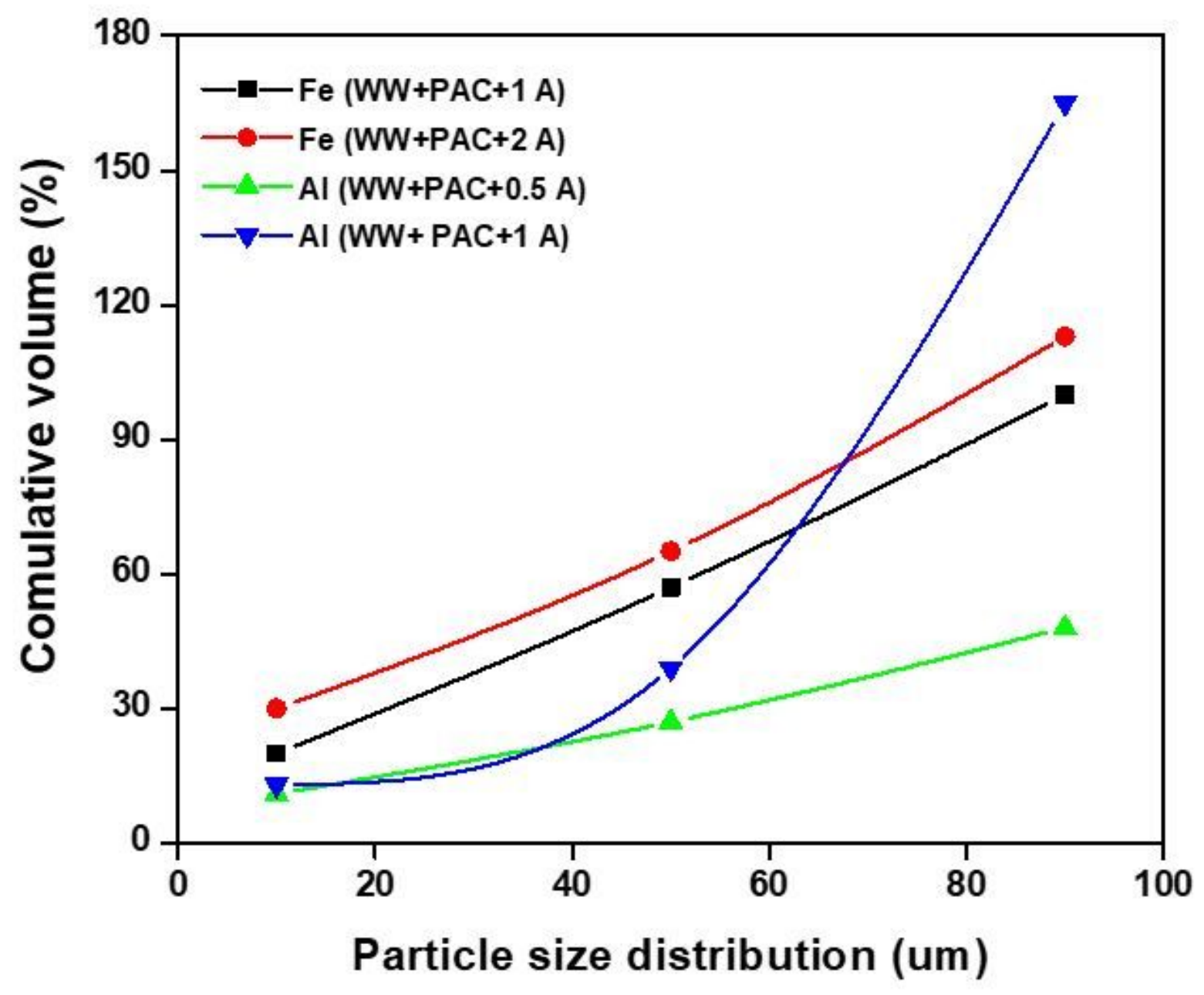

Figure 11

The particle size distribution of flocs generated by Fe and AI EC process at different values of applied current. 